\title{
Eight new species of the genus Anaplecta Burmeister, 1838 (Blattodea: Blattoidea: Anaplectidae) from China based on molecular and morphological data
}

\author{
Wenbo DENG ${ }^{1}$, Yuchao $\mathrm{LIU}^{2}$, Zongqing $\mathrm{WANG}^{3} \&$ Yanli CHE ${ }^{4, *}$ \\ ${ }^{1,2,3,4}$ Institute of Entomology, College of Plant Protection, Southwest University, \\ Beibei, Chongqing 400715, China. \\ "Corresponding author: lilyche@swu.edu.cn \\ 1Email: wenbo_deng1994@sina.com \\ 2Email: 1820614593@qq.com \\ ${ }^{3}$ Email: zqwang2006@126.com \\ 1 으 https://orcid.org/0000-0001-5796-241X \\ ${ }^{1}$ urn:1sid:zoobank.org:author:B13AC89B-B744-4B9D-9B71-CB4B4C43DC18
${ }^{2}$ urn:1sid:zoobank.org:author:C5182947-DF31-4FA5-AC28-EBC85EC87B59
${ }^{3}$ urn:1sid:zoobank.org:author:63A3EAD5-ADC0-408C-A24C-04247463B9A1
${ }^{4}$ urn:1sid:zoobank.org:author:8ED9AE03-E0EB-4DCE-BE08-658582983CC4
}

Abstract. In this study, we examine 500 specimens of Anaplecta collected from China, of which 26 samples were used for $C O I$ sequencing. We confirm eight new species, i.e., Anaplecta corneola Deng \& Che sp. nov., Anaplecta staminiformis Deng \& Che sp. nov., Anaplecta arcuata Deng \& Che sp. nov., Anaplecta strigata Deng \& Che sp. nov., Anaplecta furcata Deng \& Che sp. nov., Anaplecta cruciata Deng \& Che sp. nov., Anaplecta nigra Deng \& Che sp. nov. and Anaplecta bicolor Deng \& Che sp. nov. based on morphological and molecular data using ABGD and GMYC analyses. The results of ABGD and GMYC were basically consistent with the morphospecies of Anaplecta. The intraspecific and interspecific genetic distances of Anaplecta ranged from 0 to $6.6 \%$ and $16.8 \%$ to $31.8 \%$, respectively. We found the male genitalia of Anaplecta to exhibit intraspecific variation, especially in the phallomeres.

Keywords. ABGD, Anaplectinae, COI, DNA barcodes, GMYC, male genitalia.

Deng W., Liu Y., Wang Z. \& Che Y. 2020. Eight new species of the genus Anaplecta Burmeister, 1838 (Blattodea: Blattoidea: Anaplectidae) from China based on molecular and morphological data. European Journal of Taxonomy 720: 77-106. https://doi.org/10.5852/ejt.2020.720.1117

\section{Introduction}

Compared with most other cockroaches, members of the genus Anaplecta Burmeister, 1838 are much smaller in size, with a swollen clypeus (except for the Australian species Anaplecta calosoma Shelford, 1912) and a large appendicular field on the wings (except for the Australian species Anaplecta 
brachyptera Roth, 1990). After Burmeister (1838), there were numerous taxonomists who focused on the taxonomical study of Anaplecta. Walker (1868) established the family Anaplectidae for this group. Kirby (1904) designated Anaplecta lateralis Burmeister, 1838 as type species for the genus. Many species of this group were described by the following taxonomists: Brunner von Wattenwyl (1865), Shelford (1906, 1908, 1909), Hanitsch (1915), Hebard (1929), Shiraki (1931), Bey-Bienko (1958, 1969) and Princis (1965). These taxonomists described one species from Oceania, eight from Africa, 28 from Asia and 45 from America. Up to now, a total of 94 species of Anaplecta have been reported worldwide (Beccaloni 2014), of which five are distributed in China.

As to the placement of Anaplecta, it was the subject of controversial opinions. Initially, Anaplecta was placed in the family Blattidae (Burmeister 1838), and then in Anaplectidae (Walker 1868). Saussure \& Zehntner (1895) assigned it to Anaplectinae under Blattidae, followed by Hebard (1929), Hanitsch (1931, 1932) and Bruijning (1948). Kirby (1904) placed Anaplecta in Blattellinae, followed by Shelford (1906, 1909), Hanitsch $(1915,1929,1930)$ and Shiraki (1931). Princis (1960) placed Anaplecta in Anaplectinae, Anaplectidae. Based on a phylogenetic study using morphological data, McKittrick (1964) placed Anaplecta in the Blattellidae, belonging to Anaplectinae, and Roth $(1990,1996,2003)$ agreed with her opinion. But Grandcolas $(1993,1996,1997,1999)$ thought this group should be upgraded to family level, under the superfamily Blaberoidea. Recently, some molecular studies (Djernæs et al. 2015; Wang et al. 2017; Bourguignon et al. 2018) showed that Anaplecta had a close genetic relationship with members in the Blattoidea instead of with cockroaches in Blaberoidea, and Anaplectidae was therefore treated as a member of Blattoidea (Djernæs 2018).

The description of Anaplecta relied mostly on the venation and color of the wings (Shelford 1906) and not on the male genitalia; but in many cases, the venation and color are unstable (Bruijning 1948). Roth (1990) further supported Bruijning's view and pointed out that Anaplecta needed to be revised and redescribed using male genitalia when available. However, members of Anaplecta exhibit an intraspecific variation in the male genitalia (W.B. Deng, personal observation): L2d concave or spiny as well as a different position of the spine on R1. Therefore, it is challenging to distinguish species of Anaplecta only based on morphological characters. To clarify the situation, we obtained 26 COI sequences of Anaplecta spp. in order to check the reliability of the morphological data in distinguishing species. Photographs of male individuals of the new species described are provided.

\section{Material and methods}

\section{Morphological study}

All specimens were collected in Hainan, Hunan, Fujian, Guangdong, Guangxi, Yunnan, Xizang, Anhui, Chongqing, Jiangsu and Sichuan in China. The morphological terminology used in this paper mainly follows McKittrick (1964), Roth (1990), Grandcolas (1996) and Li et al. (2018). The measurements are based on the specimens examined. The genitalia segments of the examined specimens were placed in a centrifuge tube containing $10 \% \mathrm{NaOH}$ and soaked in hot water at $98^{\circ} \mathrm{C}$ for 10 minutes, rinsed with distilled water, and stored in glycerin for observation. All segments were observed in a glycerin jelly using a Motic K400 stereo microscope. Photographs of the genitalia and body were taken using a Leica M205A stereo microscope with a Leica DFC camera. All photos and images were edited with Adobe Photoshop CS6.

$\begin{array}{ll}\text { Abbreviations } & \\ \mathrm{cfd} & =\text { cubitus fold } \\ \mathrm{CuA} & =\text { cubitus anterior } \\ \mathrm{CuP} & =\text { cubitus posterior } \\ \mathrm{L} 1, \mathrm{~L} 2, \mathrm{~L} 3 & =\text { sclerites of the left phallomere }\end{array}$




$\begin{array}{ll}\mathrm{L} 2 \mathrm{~d} & =\mathrm{L} 2 \text { dorsal } \\ \mathrm{L} 2 \mathrm{v} & =\mathrm{L} 2 \text { ventral } \\ \mathrm{L} 2 \mathrm{vm} & =\text { median sclerite } \\ \mathrm{M} & =\text { media } \\ \mathrm{Pcu} & =\text { postcubitus } \\ \mathrm{R} & =\text { radius } \\ \mathrm{RA} & =\text { radius anterior } \\ \mathrm{RP} & =\text { radius posterior } \\ \mathrm{R} 1, \mathrm{R} 2, \mathrm{R} 3 & =\text { sclerites of the right phallomere } \\ \mathrm{vfd} & =\text { vannal fold } \\ \mathrm{V}[1] & =\text { the anterior one of the vannal vein } \\ \mathrm{V}[\mathrm{S}] & =\text { the other element of vannal vein }\end{array}$

\section{Institutional abbreviation}

SWU $=$ Southwest University, Chongqing, China

\section{Collection localities abbreviations}

$\begin{array}{ll}\text { Baoting, Hainan } & =\mathrm{BT} \\ \text { Beibei, Chongqing } & =\mathrm{CQ} \\ \text { Mengla, Yunnan } & =\mathrm{ML} \\ \text { Menglun, Yunnan } & =\mathrm{YN} 2 \\ \text { Motuo, Xizang } & =\mathrm{XZ} \\ \text { Mount Emei, Sichuan } & =\mathrm{SC} \\ \text { Mount Huangshan, Anhui } & =\mathrm{AH} \\ \text { Mount Wuyi, Fujian } & =\mathrm{WY} \\ \text { Mt. Dayao, Guangxi } & =\mathrm{GX} \\ \text { Mt. Diaoluo, Hainan } & =\mathrm{DLS} \\ \text { Mt. Jianfengling, Hainan } & =\mathrm{JFL} \\ \text { Mt. Limu, Hainan } & =\mathrm{LMS} \\ \text { Mt. Mangshan, Hunan } & =\mathrm{MS} \\ \text { Mt. Taimu, Fujian } & =\mathrm{TMS} \\ \text { Nanjing, Jiangsu } & =\mathrm{JS} \\ \text { Xishuangbanna, Yunnan } & =\mathrm{YN} 1 \\ \text { Zhaoqing, Guangdong } & =\mathrm{ZQ}\end{array}$

\section{PCR amplification and sequencing}

The legs and thoracic muscle were used for molecular studies; other body parts were stored in 95\% ethanol as voucher specimens. A total of 26 specimens were used for $C O I$ sequencing in this study. All sequences are deposited at the National Center for Biotechnology Information GenBank (Table 1). The extraction procedure was according to the Hipure Tissue DNA Mini Kit. The total DNA was stored at $-20^{\circ} \mathrm{C}$. Primers for the amplifications are $\mathrm{COI}$-F3 (5'-CAACYAATCATAAAGANATTG GAAC-3') and COI-R3 (5'-TAAACTTCTGGRTGACCAAARAATCA-3'). The amplification conditions were: initial denaturation at $98^{\circ} \mathrm{C}$ for $2 \mathrm{~min}$, followed by 35 cycles of $10 \mathrm{~s}$ at $98^{\circ} \mathrm{C}, 10 \mathrm{~s}$ for $51{ }^{\circ} \mathrm{C}$, and $15 \mathrm{~s}$ for $72^{\circ} \mathrm{C}$, with final extension of $2 \mathrm{~min}$ at $72^{\circ} \mathrm{C}$. Laboratory reagents were provided by TsingKe Co, Ltd., People's Republic of China. All voucher specimens are deposited in College of Plant Protection, Southwest University. 


\section{Sequence processing and phylogenetic analyses}

A total of 31 COI sequences were analyzed (26 sequences representing species of Anaplecta, 3 sequences representing species of Periplaneta Burmeister, 1838, and 2 sequences representing a mantis outgroup downloaded from GenBank; no appropriate Anaplecta COI data of other countries could be found on GenBank) (Table 1). All COI sequences were aligned using MEGA 7.0 and adjusted visually after translation into amino acid sequences. The genetic divergence value was quantified based on the Kimura 2-parameter (K2P) distance model (Kimura 1980) by MEGA 7. Maximum Likelihood (ML) analysis was implemented in RAxML 7.3.0 (Stamatakis et al. 2008) using a GTRGAMMA model with 1000 bootstrap replicates.

We also performed two molecular species delimitation methods, the Automatic Barcode Gap Discovery (ABGD: Puillandre et al. 2012) and the General Mixed Yule-coalescent (GMYC: Pons et al. 2006), in order to check the reliability of new species based on morphological data. The ABGD method was available at the web interface (https://bioinfo.mnhn.fr/abi/public/abgd/abgdweb.html) and used as a simple, quick and efficient method with the default settings, by using the Jukes-Cantor (JC69) and $\mathrm{p}$ distance model with relative gap width $(\mathrm{X}=1.0)$. The GMYC method requires a fully-resolved ultrametric tree for this analysis to define species. Time-resolved gene trees were inferred in BEAST 1.8.1 (Drummond \& Rambaut 2007) using the best models from PartitionFinder ver. 1.1.1 (Lanfear et al. 2012). The best-fitting models were as follows: COI_pos1, HKY $+\mathrm{G}$; COI_pos2, TrNef $+\mathrm{G}$; COI_pos3, $\mathrm{F} 81+\mathrm{I}$. The following settings were: rate variation modeled among branches using a strict clock model with the mean clock rate fixed to 1 and the Birth-Death speciation used as a tree prior. We elected to use the GMYC method to build the ultrametric gene tree using the SPLITS package (Ezard et al. 2009) in $\mathrm{R}$ ( $\mathrm{R}$ Code Team 2013). The species delimited were compared to a one species null model using a likelihood ratio test.

\section{Results}

\section{Morphological delimitation of Anaplecta}

On the basis of the morphology, including male genital characters, we were able to identify 11 morphospecies of Anaplecta among 500 samples examined from China (Fig. 1A).

\section{Phylogenetic analysis based on COI and MOTUs estimation}

In this study, we acquired 26 COI sequences of Anaplecta representing 11 morphospecies of Anaplecta, whose length, excluding primers, was $658 \mathrm{bp}$. All of the new sequences have been deposited in GenBank with accession numbers MT800285 to MT800310 (Table 1). The parts of COI we sequenced had a relatively high AT level (60.5\%), with an average nucleotide composition of $\mathrm{A}=29.5 \%, \mathrm{~T}=31.2 \%$, $\mathrm{G}=16.9 \%$, and $\mathrm{C}=22.4 \%$. ML analysis revealed that samples from the same morphospecies, including females, constitute monophyletic groups (Fig. 1) with high support values.

We used two molecular species delimitation methods (ABGD, GMYC) in our study to delimit species of Anaplecta. The ABGD analysis for MOTUs detection was estimated with JC69 and $\mathrm{P}=0.001$, and the likelihoods of the null and GMYC models from COI analysis were 96.16 and 117.59 , respectively. The same MOTUs were detected in both the ABGD and GMYC analyses (Fig. 1B-C) for nine morphospecies, which were recovered as single MOTU in both methods. There was a minor difference in these two analyses: four samples of $A$. corneola Deng \& Che sp. nov. were recovered as one single MOTU in the ABGD method, which is consistent with the result based on morphological data, while they were recovered as two MOTUs in GMYC (Fig. 1B-C). 


\section{Establishment of eight new species after evaluating morphological and molecular data}

The number of MOTUs recovered from our ABGD analyses (Fig. 1B) is nearly consistent with the number of morphological species (Fig. 1A) that we identified, and almost conform with the result from the GMYC analyses (Fig. 1C). The only discrepancy between the two molecular species delimitation methods were the four samples (JFL1, WY, ZQ and MS) from Hainan, Fujian, Guangdong and Hunan, which were recovered as two MOTUs in GMYC but one in ABGD. These four samples exhibit a high similarity in morphology but, after careful examination, we found a slight difference in R1 besides size (Fig. 10F-I): samples from ZQ (Fig. 10F) and JFL1 (Fig. 10G) almost the same, sample from WY (Fig. 10I) with first spine at tip, while sample from MS (Fig. 10H) with spines around upper-middle part. Although there was the larger genetic distance among these four samples (Supplementary File 1: 6.5\%

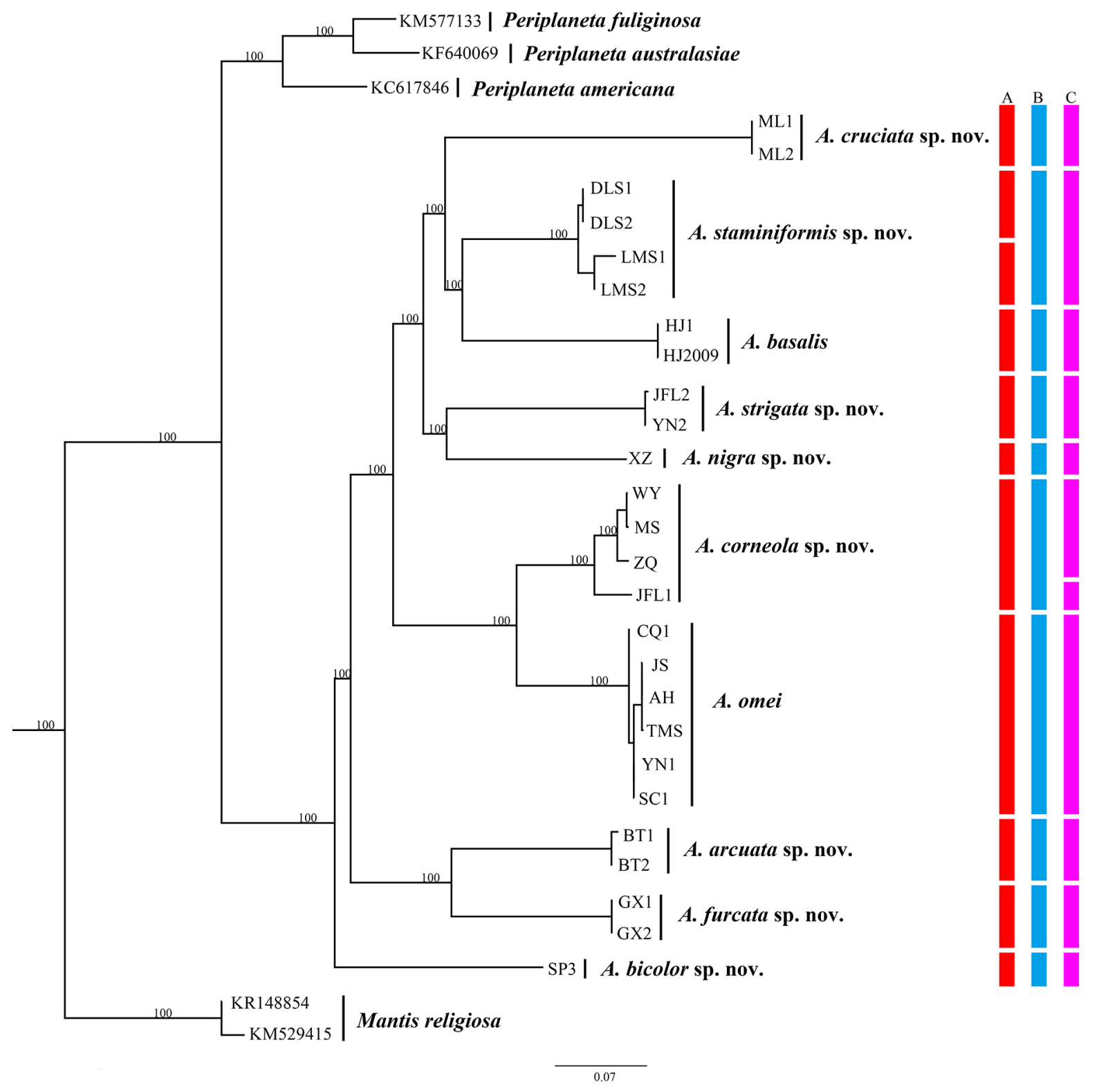

Fig. 1. Maximum-likelihood (ML) tree derived from COI gene analysis following GTR GAMMA model with 1000 bootstrap replicates. Colored bars in red refer to the morphospecies, those in blue to MOTUs in ABGD and those in purple to MOTUs in GMYC. 
Table 1. Samples used in species delimitation: sample collection localities, specimen voucher, and GenBank accession number.

\begin{tabular}{|c|c|c|}
\hline Species & Location & Accession Number (Specimen voucher number) \\
\hline \multirow{6}{*}{ A. отеі } & Beibei, Chongqing & MT800285 (CQ1) \\
\hline & Nanjing, Jiangsu & MT800287 (JS) \\
\hline & Mount Huangshan, Anhui & MT800288 (AH) \\
\hline & Mt. Taimu, Fujian & MT800286 (TMS) \\
\hline & Xishuangbanna, Yunnan & MT800290 (YN1) \\
\hline & Mount Emei, Sichuan & MT800289 (SC1) \\
\hline A. basalis & Xishuangbanna, Yunnan & MT800305, MT800309 (HJ2009, HJ1) \\
\hline A. nigra sp. nov. & Motuo, Xizang & MT800305 (XZ) \\
\hline \multirow{4}{*}{ A. corneola sp. nov. } & Mt. Jianfengling, Hainan & MT800293 (JFL1) \\
\hline & Mount Wuyi, Fujian & MT800296 (WY) \\
\hline & Zhaoqing, Guangdong & MT800295 (ZQ) \\
\hline & Mt. Mangshan, Hunan & MT800294 (MS) \\
\hline \multirow{2}{*}{ A. staminiformis sp. nov. } & Mt. Diaoluo, Hainan & MT800297, MT800298 (DLS1, DLS2) \\
\hline & Mt. Limu, Hainan & MT800299, MT800300 (LMS1, LMS2) \\
\hline A. arcuata sp. nov. & Baoting, Hainan & MT800307, MT800308 (BT1, BT2) \\
\hline \multirow{2}{*}{ A. strigata sp. nov. } & Mt. Jianfengling, Hainan & MT800291 (JFL2) \\
\hline & Menglun, Yunnan & MT800292 (YN2) \\
\hline A. furcata sp. nov. & Mt. Dayao, Guangxi & MT800301, MT800302 (GX1, GX2) \\
\hline A. bicolor sp. nov. & Xishuangbanna, Yunnan & MT800310 (SP3) \\
\hline A. cruciata sp. nov. & Mengla, Yunnan & MT800303, MT800304 (ML1, ML2) \\
\hline Periplaneta americana & Indiana, USA & KC617846 \\
\hline Mantis religiosa & Ontario, Canada & KM529415 \\
\hline Mantis religiosa & Ontario, Canada & KR148854 \\
\hline Periplaneta fuliginosa & Buenos Aires, Argentina & KM577133 \\
\hline Periplaneta australasiae & China & KF640069 \\
\hline
\end{tabular}

between ZQ and JFL1, 6.6\% between MS and JFL1), we considered the slight morphological differences between these samples (Fig. 10F-I) as intraspecific variation, not as interspecific difference, conforming to the result of the morphological identification. Another discrepancy existed between the morphological identification and the molecular species delimitation in specimens from Mt. Diaoluo (DLS) and Mt. Limu (LMS), which exhibit some difference in L2d: a sample from DLS is bifurcated (Fig. 3L), while a sample from LMS is spiny (Fig. 3O); and R2: a sample from DLS is slender (Fig. 3M), while the other is flat (Fig. 3P). But according to the genetic distance between them (1.9\%) and the absence of other morphological differences, the difference of L2d and R2 between the two morphospecies should be considered as an intraspecific variation. Therefore, we identified ten species of Anaplecta among the 500 samples using morphological and molecular data (Fig. 1), of which eight are new to science, i.e., A. corneola Deng \& Che sp. nov., A. staminiformis Deng \& Che sp. nov., A. arcuata Deng \& Che sp. nov., A. strigata Deng \& Che sp. nov., A. furcata Deng \& Che sp. nov., A. cruciata Deng \& Che sp. nov., A. nigra Deng \& Che sp. nov., and A. bicolor Deng \& Che sp. nov. (Figs 2-9).

The intraspecific and interspecific genetic distances of Anaplecta ranged from 0 to $6.6 \%$ and $16.8 \%$ to $31.8 \%$, respectively (Supplementary File 1). 


\title{
Taxonomy
}

\author{
Class Insecta Linnaeus, 1758 \\ Order Blattodea Brunner von Wattenwyl, 1882 \\ Superfamily Blattoidea Latreille, 1810 \\ Family Anaplectidae Walker, 1868 \\ Subfamily Anaplectinae Walker, 1868
}

Genus Anaplecta Burmeister, 1838

Anaplecta Burmeister, 1838: 494.

Anaplecta-Hebard 1929: 27. — Bruijning 1948: 43. — Princis 1965: 367. — Roth 1990: 645; 1996: 304; 2003: 36. - Beccaloni 2014.

\section{Type species}

Anaplecta lateralis Burmeister, 1838.

\section{Diagnosis}

Sexual dimorphism indistinct. Size small. Body smooth. Color ranging from brownish yellow to dark brown. Eyes large, wide apart. Ocelli absent, or only indicated by two dim white spots. Antennae longer than body length. Clypeus distinct, swollen (except for Australian species A. calosoma Shelford, 1912). Tegmina and wings: usually fully developed, both extending over the end of abdomen (except for Australian species A. brachyptera Roth, 1990). Tegmina narrow, usually with three longitudinal or sublongitudinal sectors. Wings often infuscated, radial field and part of appendicular field darker than remaining part and with large appendicular field about $40 \%$ of wings; costal veins and radial veins sometimes obvious, sometimes indistinct; two weakly developed veins, one longitudinal along fold, the other somewhat oblique in appendicular field. Legs: front femur type B2. Pulvilli absent or apparent on the fourth proximal tarsomere only. Claws usually simple, rarely serrated, symmetrical. Arolia present. Abdomen: male: middle area of supra-anal plate with a cluster of pubescence; apical margin convex, with long setae. Subgenital plate generally symmetrical; styli cylindrical with setae; female: subgenital plate valvular. Genitalia: male: hook (L3) on left.

\section{Distribution}

North America, South America, Africa, Asia, Oceania.

\section{Key to species of Anaplecta in China}

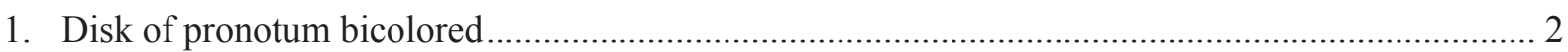

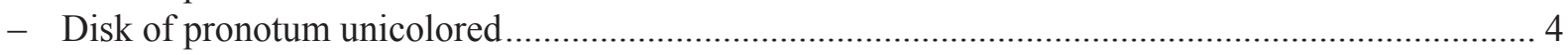

2. Disk of pronotum dark brown with median yellowish-brown through anterior to posterior

A. strigata Deng \& Che sp. nov.

- Disk of pronotum with anterior half crimson-brown, posterior half yellowish-white

3. Tegmina with anal area dark brown, the rest yellow (except the hyaline lateral margins) A. basalis Bey-Bienko, 1969

- Tegmina brownish (except the hyaline lateral margins) A. bicolor Deng \& Che sp. nov.

4. Tegmina with anal area black, the rest yellow (except the hyaline basal lateral margins)

- Tegmina unicolored (except the hyaline lateral margins) A. nigra Deng \& Che sp. nov. 
5. Three to four cross-veins in mediocubital field of wings A. malayensis Shelford, 1906

- Five to seven cross-veins in mediocubital field of wings 6

6. Paraprocts specialized, right paraproct with many spines on curly posterior marign, or left paraproct

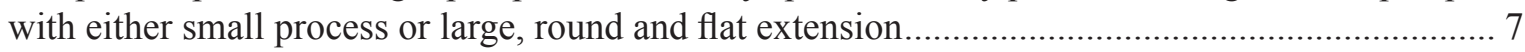

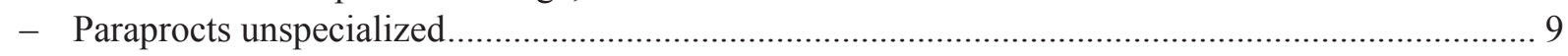

7. Right paraproct with many short, stout spines on curly posterior margin

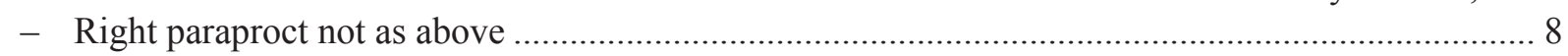

8. Left paraproct with a small process.

A. cruciata Deng \& Che sp. nov.

- Left paraproct with a large, round and flat extension A. furcata Deng \& Che sp. nov.

9. Right phallomere degraded or absent A. arcuata Deng \& Che sp. nov.

- Right phallomere present. 10

10. Right phallomere with special horny structure A. corneola Deng \& Che sp. nov.

- Right phallomere with irregular bone sheet. A. staminiformis Deng \& Che sp. nov.

\section{Anaplecta corneola Deng \& Che sp. nov. urn:lsid:zoobank.org:act:6D7952AF-00D8-4E8C-973E-F04B2DDCBA68}

Figs 2, 10F-I

\section{Diagnosis}

This species resembles Anaplecta omei, but can be distinguished from it by the following characters: 1) paraprocts simple, sheet-like in $A$. corneola Deng \& Che sp. nov., while right paraproct with many short, stout spines on curly posterior margin in $A$. omei; 2) right phallomere with horn-shaped structure (R1) in A. corneola Deng \& Che sp. nov., absent in A. omei.

\section{Etymology}

The specific name is derived from the Latin word 'corneolus', referring to the right phallomere with a horn-shaped structure.

\section{Type material}

\section{Holotype}

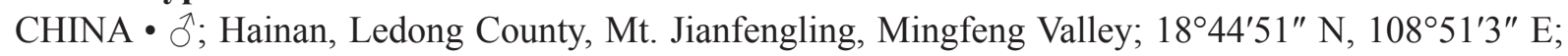
798 m a.s.1.; 26-28 May 2014; Shun-hua Gui, Xin-ran Li and Jian-yue Qiu leg.; SWU.

\section{Paratypes}

CHINA - Hainan • 1 đ̧; same collection data as for holotype; 28 Apr. 2013; Shun-hua Gui and Yan

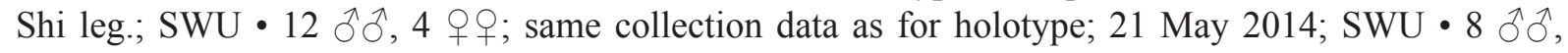
12 우; same collection data as for holotype; SWU • $2 \hat{\jmath} \widehat{\hat{0}, 3}, 3$ 우; same collection data as for holotype; 23 Apr. 2015; Lu Qiu and Qi-kun Bai leg.; SWU. - Guangdong • 4 ${ }^{\jmath}, 3$ 우; Guangzhou City, Tianhe

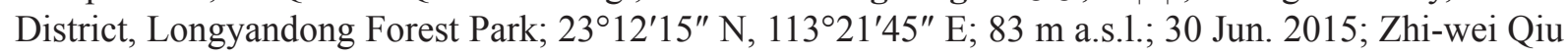

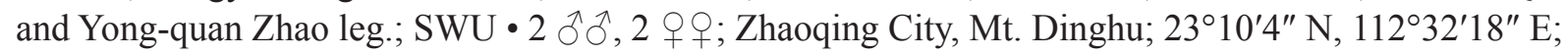
$351 \mathrm{~m}$ a.s.1.; 1 Jul. 2015; Zhi-wei Qiu and Yong-quan Zhao leg.; SWU • 3 o+ 0 ; Shaoguan City, Mt.

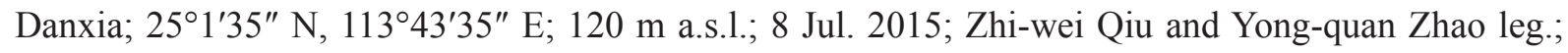

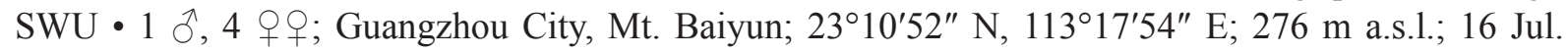



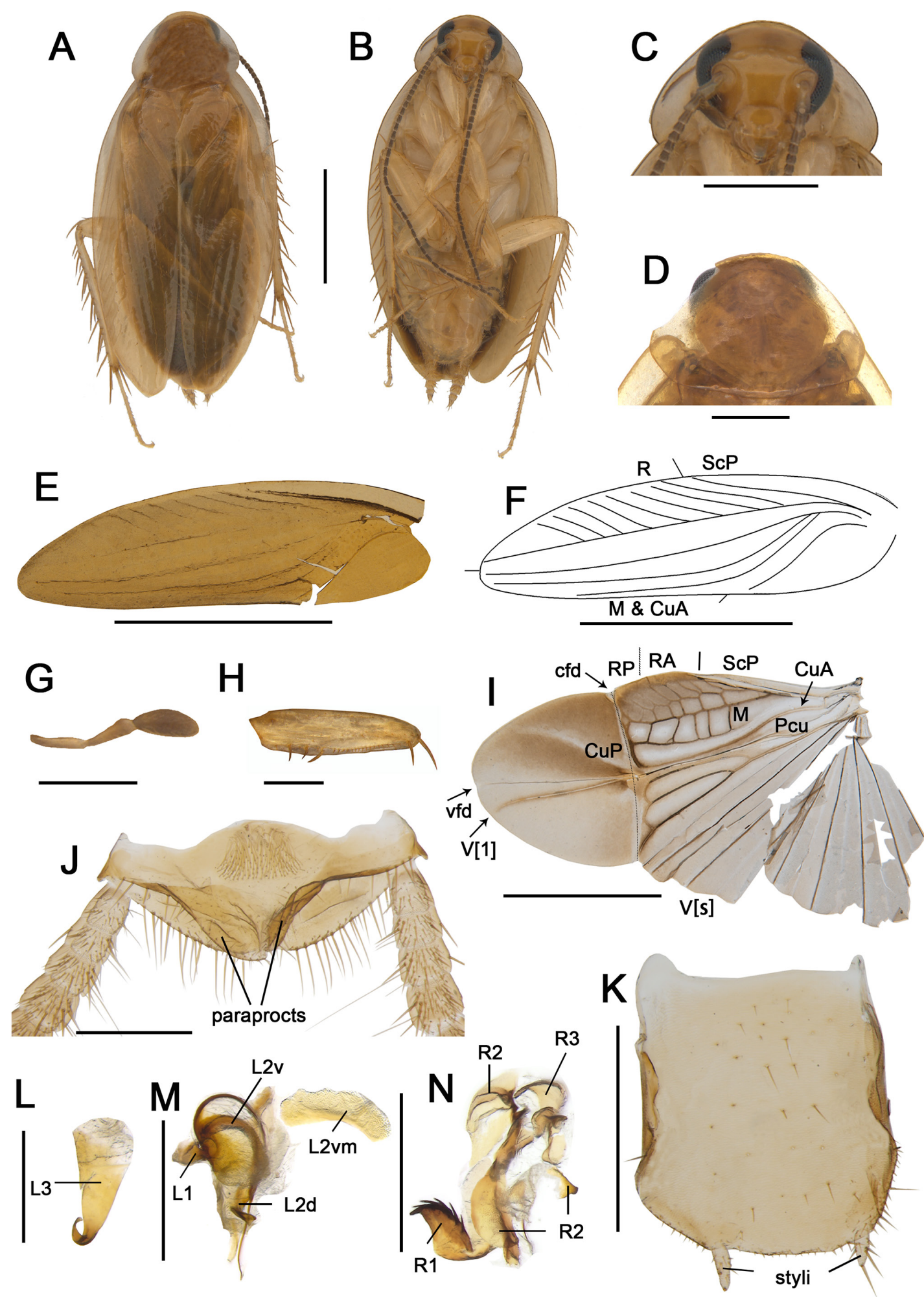

Fig. 2. Anaplecta corneola Deng \& Che sp. nov., holotype, ô (SWU). A. Habitus, dorsal view. B. Habitus, ventral view. C. Head, ventral view. D. Pronotum, dorsal view. E. Tegmina. F. Tegmina vein. G. Maxillary palp. H. Front femur, ventral view. I. Wings. J. Supra-anal plate, dorsal view. K. Subgenital plate, ventral view. L. Hook, ventral view. M. Left phallomere, ventral view. N. Right phallomere, ventral view. Scale bars: A-B, E-F, I=2 mm; C, G-H=1 mm; D, J-K, M-N=0.5 mm; $\mathrm{L}=0.25 \mathrm{~mm}$. 


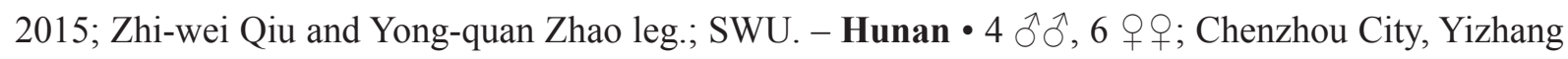
County, Mangshan Forest Park; 245ㄱ'26" N, 11255'21" E; 954 m a.s.1.; 11 Jul. 2015; Zhi-wei Qiu and

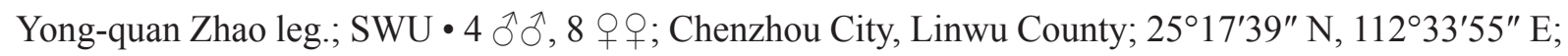
389 m a.s.l.; 14 Jul. 2015; Zhi-wei Qiu and Yong-quan Zhao leg.; SWU. - Fujian • 1 ð, 1 q; Wuyishan City, Tongmu; 27 44'50" N, 11740'46" E; 759 m a.s.l.; 10 Jul. 2013; Shun-hua Gui and Yan Shi leg.; SWU.

\section{Description}

\section{Male}

Measurements $(\mathrm{mm})$. Male: pronotum length $\times$ width: $1.6-1.8 \times 2.0-2.2$, tegmina length: $5.8-6.2$, overall length: $6.5-7.2$. Female: pronotum length $\times$ width: $1.7-1.9 \times 2.1-2.3$, tegmina length: $5.6-5.9$, overall length: $6.7-6.8$.

Coloration. Body yellowish brown, eyes black, antennae dark brown (Fig. 2A-B). Head yellowish brown (Fig. 2C). Pronotum and tegmina yellowish brown, lateral borders of pronotum nearly hyaline (Fig. 2D-E). Wings with costal field and appendicular field infuscated, other part pale gray, with veins brown (Fig. 2I). Abdominal sterna, legs and cerci yellowish brown (Fig. 2B).

HEAD AND THORAX. Interocular space slightly greater than distance between antennal sockets (Fig. 2C). Third, fourth and fifth maxillary palpi nearly equal in length, fifth maxillary palpus slightly thicker than fourth maxillary palpus, which is nearly oval (Fig. 2G). Pronotum subelliptical (Fig. 2D). Tegmina with veins basically distinct; wings with radial veins slightly indistinct, $\mathrm{CuP}$ and $\mathrm{CuA}$ merging into one venation (Fig. 2E-F, I). Front femur type B2 (Fig. 2H). Pulvilli absent, arolia present.

Male ABdomen And genitalia. Supra-anal plate with paraprocts almost the same and sheet-like (Fig. 2J). Subgenital plate nearly triangular, symmetrical; styli with length about $1 / 4$ of interstylar space, interstylar margin practically straight (Fig. 2K). Phallomere complex, L1 small, nearly triangular, with slender and curved filamentary structure, L2v broad, L2d and L2vm simple sheet-like, L3 robust, uncinate part with apex enlarged and blunt; R1 with horn-shaped structure, whose surface is spiky (spines variable in different samples, Fig. 10F-I), R2 irregular bone sheet, weakly sclerotized, and one of R2 vaguely hook-like, R3 short simple sheet-like (Fig. 2L-N).

\section{Distribution}

China (Fujian, Guangdong, Hainan, Hunan).

Anaplecta staminiformis Deng \& Che sp. nov. urn:1sid:zoobank.org:act:A15DB2BC-465B-4BC3-8590-36989490806F

Fig. 3

\section{Diagnosis}

This species can be distinguished from others by the following characters: 1) color darker than Anaplecta omei, Anaplecta corneola Deng \& Che sp. nov. and Anaplecta arcuata Deng \& Che sp. nov.; 2) pronotum without special markings, which is different from Anaplecta basalis, Anaplecta bicolor Deng \& Che sp. nov. and Anaplecta strigata Deng \& Che sp. nov.; 3) left phallomere with concave or spiny bone sheet at the bottom (L2d), unlike other species. 
DENG W. et al., Eight new species of Anaplecta (Blattodea: Blattoidea: Anaplectidae) from China

\section{Etymology}

The specific name is derived from the Latin word 'staminiformis' and refers to L2vm being stamenshaped.

\section{Type material}

\section{Holotype}

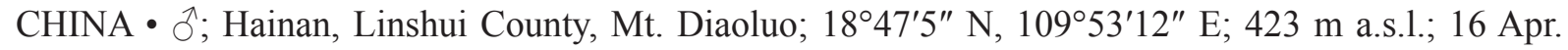
2015; Lu Qiu and Qi-kun Bai leg.; SWU.

\section{Paratypes}

CHINA - Hainan • 1 $\widehat{\jmath}$; same collection data as for holotype; 4 May 2013; Shun-hua Gui and Yan

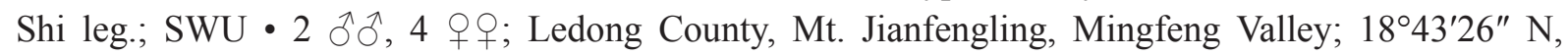
108 48'27" E; 579 m a.s.l.; 18 May 2014; Shun-hua Gui, Xin-ran Li and Jian-yue Qiu leg.; SWU • 2 우; same collection data as for holotype; SWU • 4 $\widehat{\jmath}, 2$ 우; Qiongzhong County, Mt. Limu;

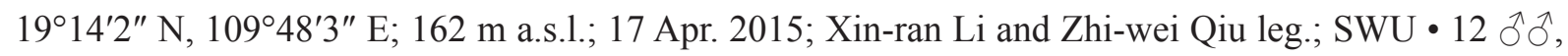
3 우, same collection data as for preceding but 18 Apr. 2015; SWU 1 ภ 3 , 3 + $ᄋ$; same collection data as for preceding but 15 May 2015; SWU.

\section{Description}

\section{Male}

Measurements $(\mathrm{mm})$. Male: pronotum length $\times$ width: $1.5-1.7 \times 2.0-2.2$, tegmina length: 5.9-6.2, overall length: $7.5-7.9$. Female: pronotum length $\times$ width: $1.8-1.9 \times 2.0-2.2$, tegmina length: $6.2-6.4$, overall length: 7.1-7.6.

Coloration. Body dark yellowish brown, eyes black, antennae dark brown (Fig. 3A-B). Vertex with frons nearly reddish brown, the other part dark yellowish brown (Fig. 3C). Pronotum dark brown, lateral borders of pronotum nearly hyaline (Fig. 3D). Tegmina dark yellowish brown, lateral margins of tegmina nearly hyaline (Fig. 3G). Wings with costal field and appendicular field infuscated, other part brown, with veins dark brown (Fig. 3H). Abdominal sterna, legs and cerci dark yellowish brown (Fig. 3B).

HEAD AND THORAX. Interocular space greater than distance between antennal sockets (Fig. 3C). Third and fourth maxillary palpi nearly equal in length, longer than fifth maxillary palpus; fifth maxillary palpus strongly thicker than fourth, which is nearly triangular (Fig. 3E). Pronotum subelliptical (Fig. 3D). Tegmina with veins basically distinct; wings with radial veins slightly indistinct, $\mathrm{CuP}$ and $\mathrm{CuA}$ merging into one venation (Fig. 3G-H). Front femur type B2 (Fig. 3F). Pulvilli absent, arolia present.

MALE ABDOMEN AND GENITALIA. Supra-anal plate with paraprocts almost identical, simply thickened sheetlike (Fig. 3I). Subgenital plate symmetrical, semi-oval; styli longer, finger-like, with length less than 1/2 of interstylar space, interstylar margin practically straight (Fig. 3J). Phallomere complex, L1 small, oval with slender and curved filamentary structure, L2v broad, L2vm stamen-shaped at the back, L2d like concave shaped bone sheet at bottom (L2d of some individuals spiny rather than concave in shape), L3 robust and uncinate part with apex enlarged and blunt; R1 cylinder-shaped with spine at end; R2 irregular bone-like sheet, weakly sclerotized, R3 short simple sheet-like (Fig. 3K-P).

\section{Distribution}

China (Hainan). 

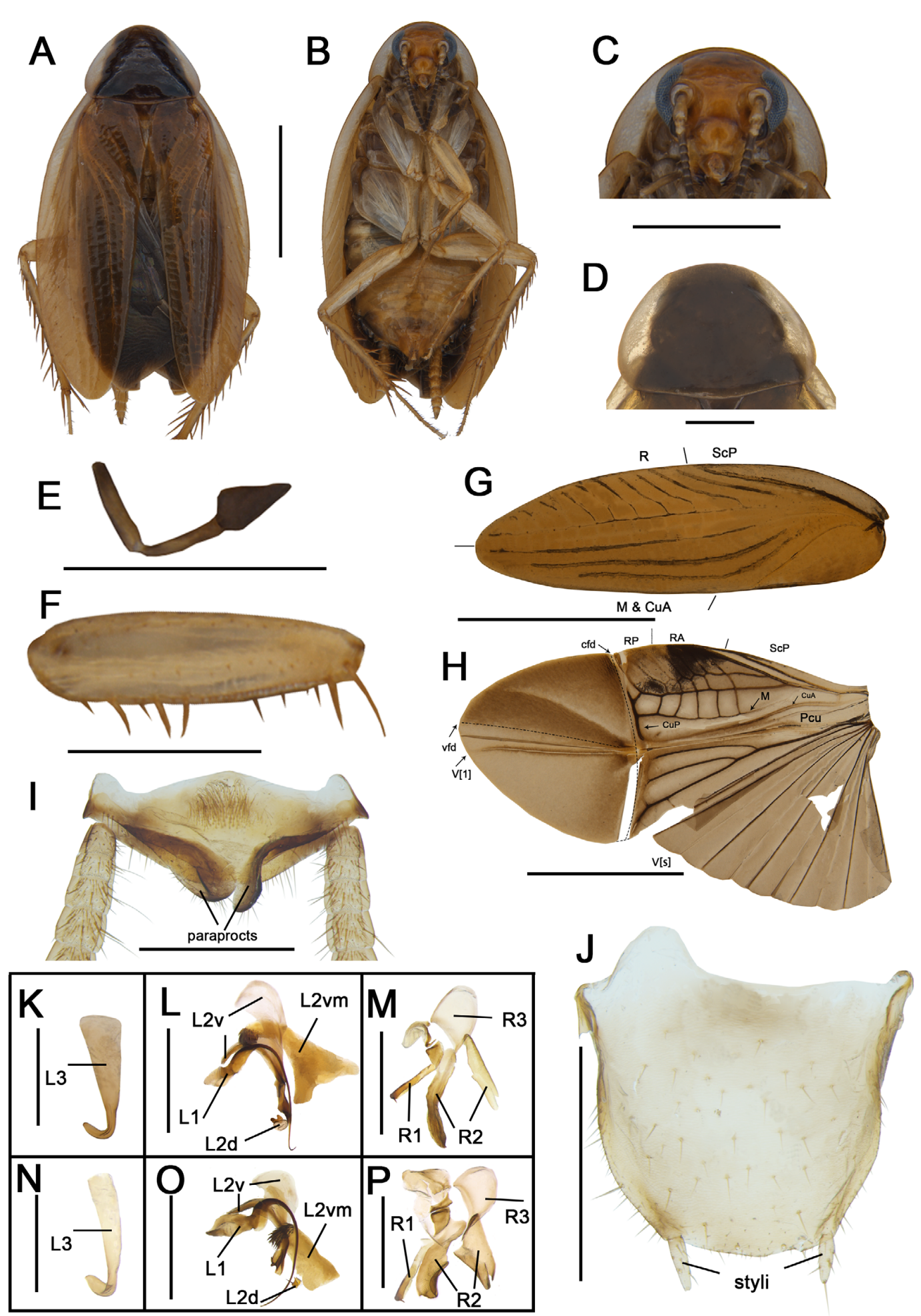

Fig. 3. Anaplecta staminiformis Deng \& Che sp. nov. A-M. Holotype, $\widehat{\jmath}$ (SWU). A. Habitus, dorsal view. B. Habitus, ventral view. C. Head, ventral view. D. Pronotum, dorsal view. E. Maxillary palp. F. Front femur, ventral view. G. Tegmina. H. Wings. I. Supra-anal plate, dorsal view. J. Subgenital plate, ventral view. K. Hook, ventral view. L. Left phallomere, ventral view. M. Right phallomere, ventral view. - N-P. Paratype, ô, samples from LMS (SWU). N. Hook, ventral view. O. Left phallomere, ventral view. P. Right phallomere, ventral view. Scale bars: A-B, G-H=2 mm; C, E-F=1 mm; D, I-J, $\mathrm{L}-\mathrm{M}, \mathrm{O}-\mathrm{P}=0.5 \mathrm{~mm} ; \mathrm{K}, \mathrm{N}=0.25 \mathrm{~mm}$. 
DENG W. et al., Eight new species of Anaplecta (Blattodea: Blattoidea: Anaplectidae) from China

\author{
Anaplecta arcuata Deng \& Che sp. nov. \\ urn:1sid:zoobank.org:act:5618EDD0-8325-4CF2-8622-7932E3AB9E97
}

Fig. 4

\title{
Diagnosis
}

Anaplecta arcuata Deng \& Che sp. nov. resembles A. corneola Deng \& Che sp. nov., but can be distinguished from it by the following characters: 1) L2vm slender with brush-like bone sheet in the former, simple sheet-like in the latter; 2) L3 with apex of uncinate part sharp in the former, enlarged and blunt in the latter. The right phallomere was not seen when examining the species, we are not sure whether it is degenerated or missing is uncertain and needs to be checked in future examinations.

\section{Etymology}

The specific name is derived from the Latin word 'arcuatus', meaning that the brush-like bone sheet (L2vm) looks like a bent bow-like arcuate structure.

\section{Type material}

\section{Holotype}

CHINA • `’; Hainan, Baoting County, Maogan; 18³6'27" N, 109³0'39" E; 564 m a.s.l.; 13 Apr. 2015; Lu Qiu and Qi-kun Bai leg.; SWU.

\section{Paratypes}

CHINA $\bullet 1$ O, 1 क ; same collection data as for holotype; SWU.

\section{Description}

\section{Male}

MEASUREMENTS (mm). Male: pronotum length $\times$ width: $1.4-1.6 \times 1.6-2.2$, tegmina length: $5.1-5.4$, overall length: $6.4-7.4$. Female: pronotum length $\times$ width: $1.3 \times 1.8$, tegmina length: 4.7 , overall length: 6.3 .

Coloration. Body yellowish brown, eyes black, antennae dark brown (Fig. 4A-B). Head yellowish brown (Fig. 4C). Pronotum and tegmina yellowish brown, lateral borders of pronotum nearly hyaline (Fig. 4D, G). Wings with costal field and appendicular field infuscated, other part pale yellow, with veins brown (Fig. 4H). Abdominal sterna, legs and cerci pale yellow (Fig. 4B, I).

HEAD AND THORAX. Interocular space greater than distance between antennal sockets (Fig. 4C). Third, fourth and fifth maxillary palpi subequal in length, fifth maxillary palpus thicker than fourth, which is nearly triangular (Fig. 4E). Pronotum subparabolic (Fig. 4D). Tegminal with veins distinct; wings with radial veins slightly indistinct, $\mathrm{CuA}$ ending at $\mathrm{CuP}$ (Fig. 4G-H). Front femur type B2 (Fig. 4F). Pulvilli absent, arolia present.

Male abdomen And Genitalia. Supra-anal plate with paraprocts almost identical, simple sheet-like (Fig. 4I). Subgenital plate nearly symmetrical, semi-oval; styli with length about $1 / 3$ of interstylar space, interstylar margin arcuate (Fig. 4J). Phallomere simple, L1 small triangle with long, slender and curved filamentary structure, L2v broad, L2vm slender with brush-like bone sheet, L2d simple sheet-like, L3 robust, uncinate part with apex sharp; right phallomere degraded or absent (Fig. 4K-L).

\section{Distribution}

China (Hainan). 

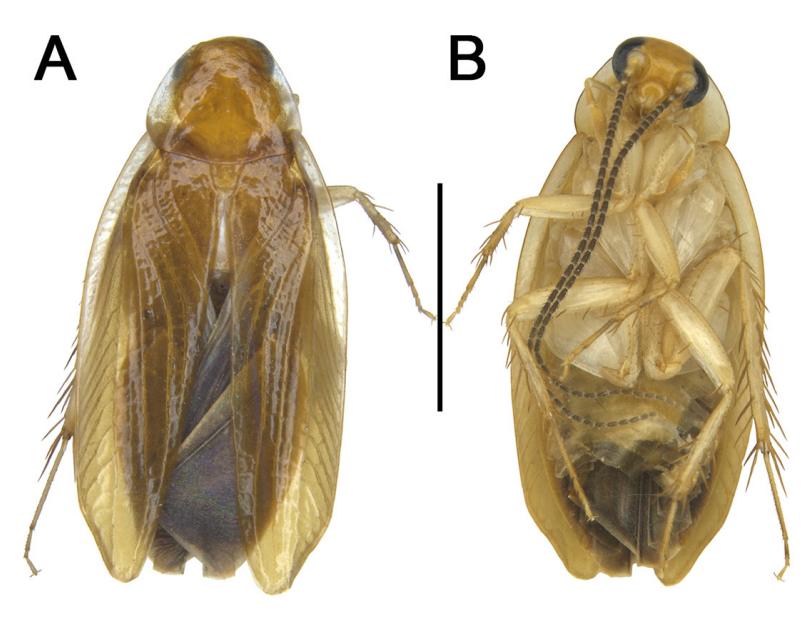

\section{C}

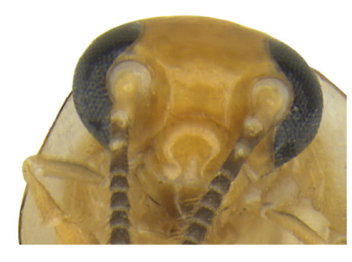

D

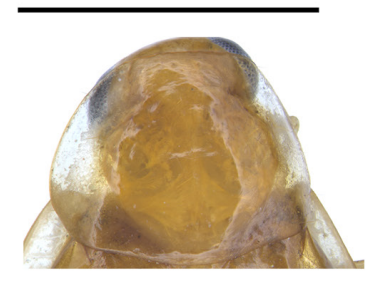

$\mathrm{E}$
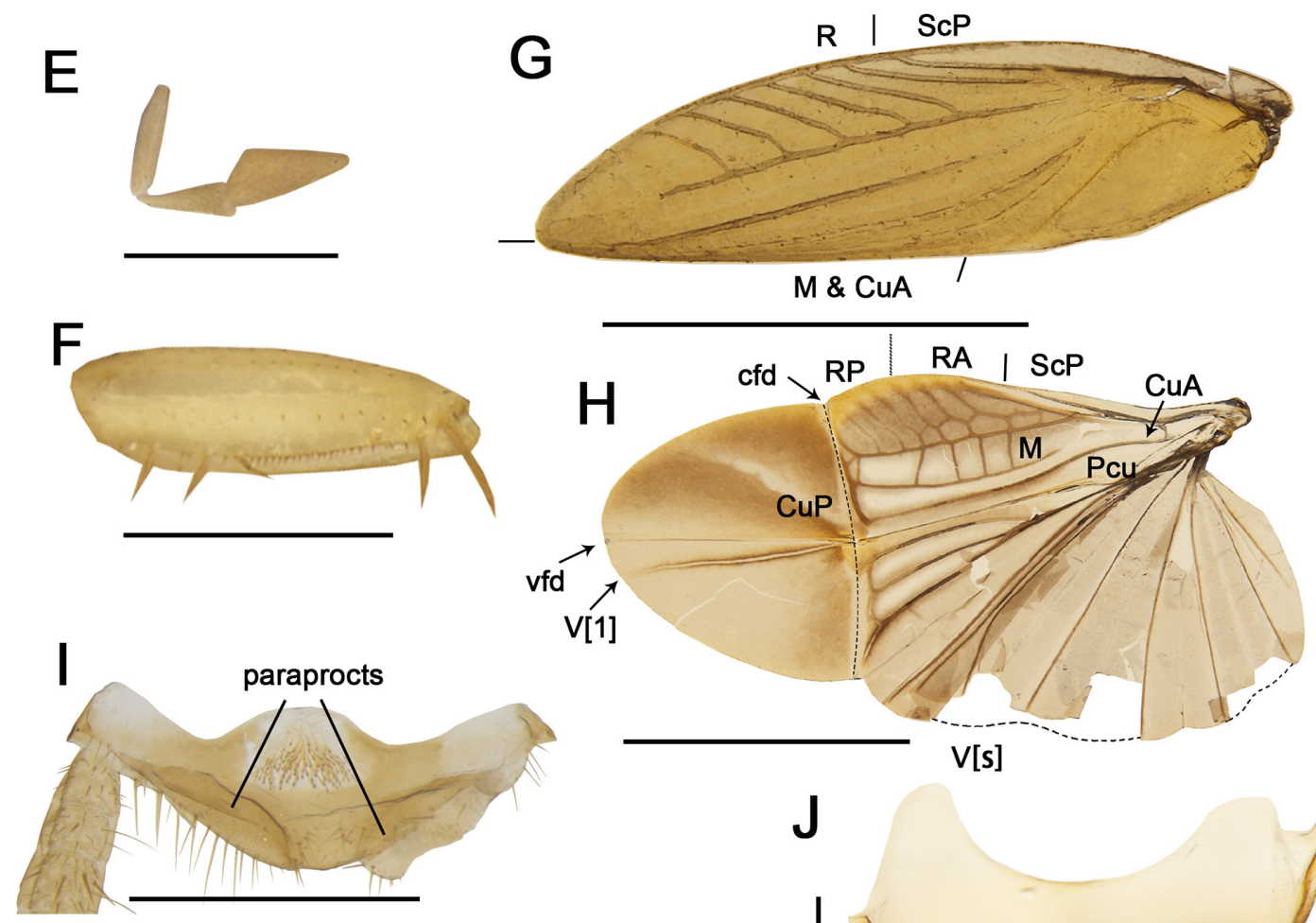

$\mathrm{V}[\mathrm{s}]$

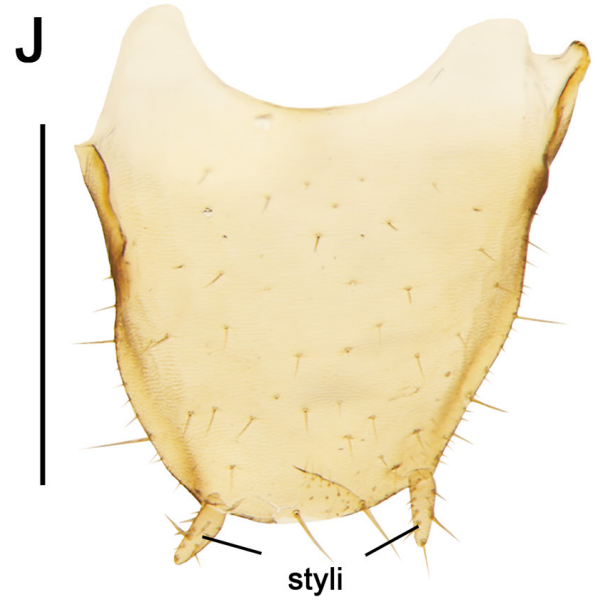

Fig. 4. Anaplecta arcuata Deng \& Che sp. nov., holotype, ô (SWU). A. Habitus, dorsal view. B. Habitus, ventral view. C. Head, ventral view. D. Pronotum, dorsal view. E. Maxillary palp. F. Front femur, ventral view. G. Tegmina. H. Wings. I. Supra-anal plate, dorsal view. J. Subgenital plate, ventral view. K. Hook, ventral view. L. Left phallomere, ventral view. Scale bars: A-B, $\mathrm{G}-\mathrm{H}=2 \mathrm{~mm}$; C=1 mm; D-F, $\mathrm{I}-\mathrm{J}=0.5 \mathrm{~mm} ; \mathrm{K}-\mathrm{L}=0.1 \mathrm{~mm}$. 
DENG W. et al., Eight new species of Anaplecta (Blattodea: Blattoidea: Anaplectidae) from China

\section{Anaplecta strigata Deng \& Che sp. nov. urn:1sid:zoobank.org:act:CD26CE89-6719-4DD7-8405-F3CE2FC95BB3}

Fig. 5

\section{Diagnosis}

This species resembles A. malayensis, but can be distinguished from it by the markings on the disk of pronotum. The former has two chocolate-brown markings on the disk of pronotum, yellowish-brown in the middle, while the latter is chocolate-brown, without markings.

\section{Etymology}

The specific name is derived from the Latin word 'strigatus' and refers to the two chocolate-brown stripes on disk of pronotum.

\section{Type material}

\section{Holotype}

CHINA - '; Hainan, Ledong County, Mt. Jianfengling, Mingfeng Valley; $18^{\circ} 43^{\prime 2} 26^{\prime \prime}$ N, 108 $48^{\prime 2} 27^{\prime \prime}$ E; 579 m a.s.1.; 26 May 2014; Shun-hua Gui, Xin-Ran Li and Jian-yue Qiu leg.; SWU.

\section{Paratypes}

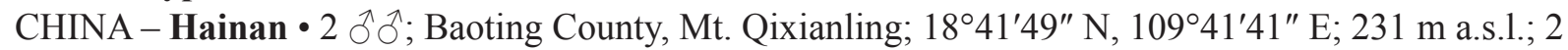

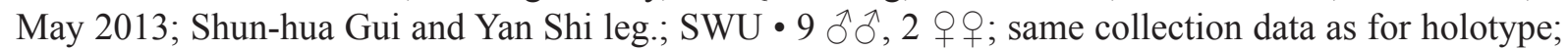
SWU • 1 गे; Qiongzhong County; 19²'22" N, 10948'51" E; 336 m a.s.1.; 12 Apr. 2015; Xin-ran Li and

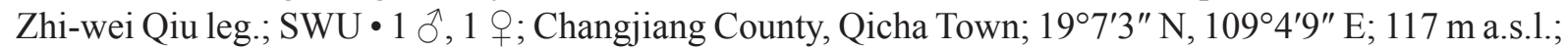

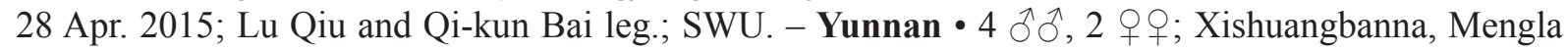

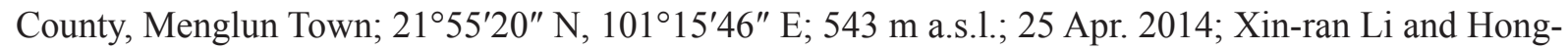
guang Liu leg.; SWU.

\section{Description}

\section{Male}

Measurements $(\mathrm{mm})$. Male: pronotum length $\times$ width: $1.0-1.3 \times 1.6-1.8$, tegmina length: $3.8-4.0$, overall length: 4.8-5.0. Female: pronotum length $\times$ width: $1.1-1.5 \times 1.6-2.0$, tegmina length: $3.8-4.1$, overall length: $6.0-6.5$.

Coloration. Body dark yellowish brown, eyes black, antennae yellowish-brown (Fig. 5A-B). Head yellowish brown (Fig. 5C). Pronotum hyaline or pale yellow, with two chocolate-brown stripes on disk, lateral borders of pronotum nearly hyaline (Fig. 5D). Tegmina dark yellowish brown, lateral margins of tegmina hyaline (Fig. 5E). Wings with costal field and appendicular field infuscated, other part pale gray, with veins yellowish brown (Fig. 5I). Abdominal sterna and cerci dark yellowish brown. Legs pale yellow (Fig. 5B).

HEAD AND THORAX. Interocular space slightly greater than the distance between antennal sockets (Fig. 5C). Fourth and fifth maxillary palpi subequal in length, shorter than third maxillary palpus, fifth maxillary palpus slightly thicker than fourth, which is nearly triangular (Fig. 5G). Pronotum subelliptical (Fig. 5D). Tegminal with veins slightly indistinct; wings with radial veins basically distinct, $\mathrm{CuP}$ and $\mathrm{CuA}$ merging into one venation (Fig. 5E-F, I). Front femur type B2 (Fig. 5H). Pulvilli absent, arolia present.

MALE ABDOMEn AND GENITALIA. Supra-anal plate with paraprocts almost identical, simple thickened sheetlike (Fig. 5J). Subgenital plate asymmetrical, with hind margin arc shaped, extending beyond end of styli; two styli small, interstylar margin convexly skewed to left (Fig. 5K). Phallomere complex, L1 

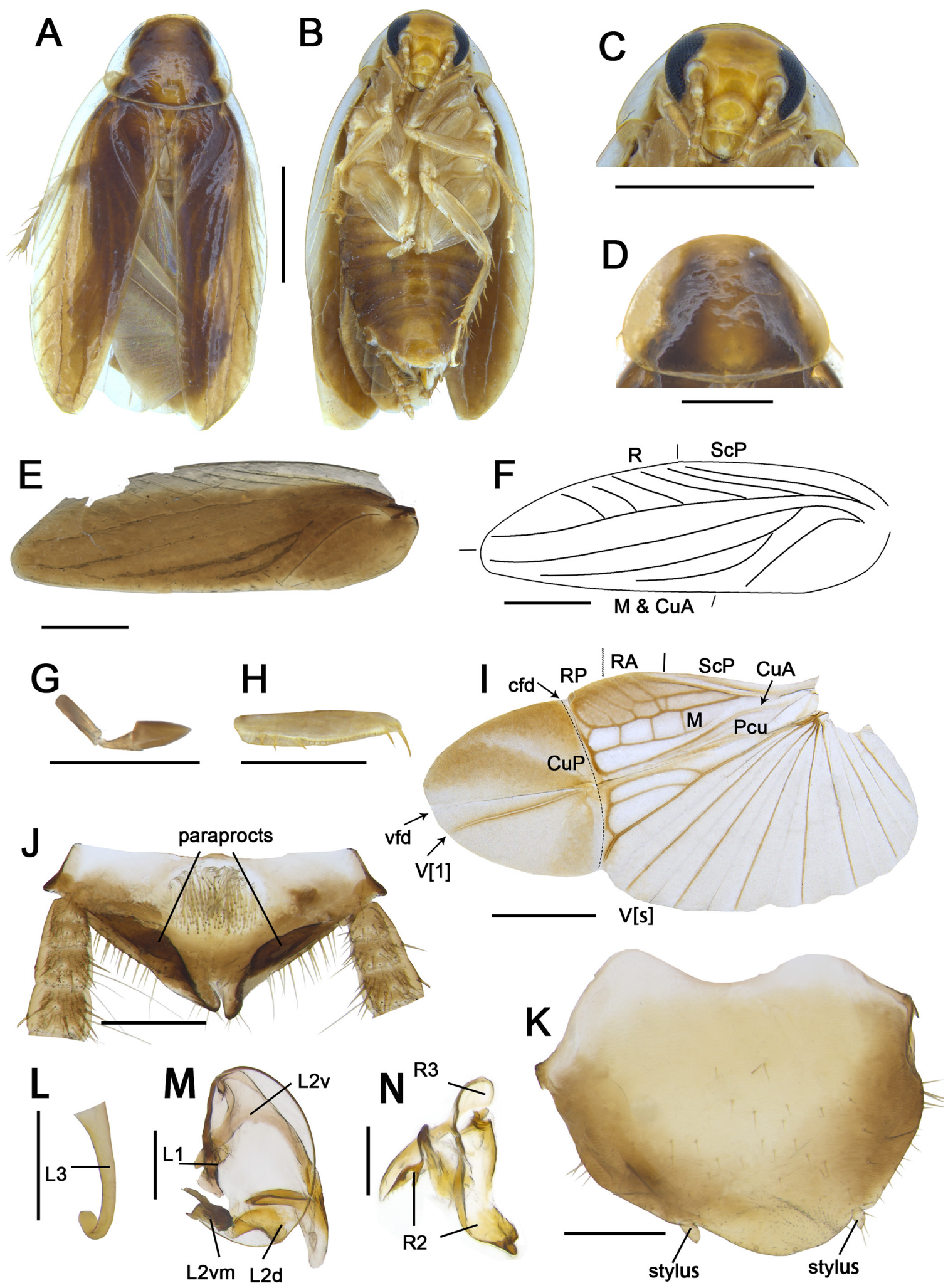

Fig. 5. Anaplecta strigata Deng \& Che sp. nov., holotype, ồ (SWU). A. Habitus, dorsal view. B. Habitus, ventral view. C. Head, ventral view. D. Pronotum, dorsal view. E. Tegmina. F. Tegmina vein. G. Maxillary palp. H. Front femur, ventral view. I. Wings. J. Supra-anal plate, dorsal view. K. Subgenital plate, ventral view. L. Hook, ventral view. M. Left phallomere, ventral view. N. Right phallomere, ventral view. Scale bars: A-B $=2 \mathrm{~mm}$; C, E-F, I $=1 \mathrm{~mm} ; \mathrm{D}, \mathrm{G}-\mathrm{H}, \mathrm{J}-\mathrm{K}, \mathrm{M}-\mathrm{N}=0.5 \mathrm{~mm}$; $\mathrm{L}=0.25 \mathrm{~mm}$. 
small triangle with long, slender and curved filamentary structure; L2v slender, handle-shaped, L2d short and bent, L2vm brush-like bone sheet, L3 robust and the uncinate part with apex enlarged and blunt; R1 absent, R2 irregular bone sheet, weakly sclerotized, R3 short simple sheet-like (Fig. 5L-N).

\section{Distribution}

China (Hainan, Yunnan).

Anaplecta furcata Deng \& Che sp. nov. urn:lsid:zoobank.org:act:6E524187-1588-4061-9B75-4E0E889571C5

Fig. 6

\section{Diagnosis}

This species resembles $A$. cruciata Deng \& Che sp. nov., but can be distinguished from it by the following characters: 1) left phallomere with filamentary structure unthickened in the former, strongly thickened in the latter; 2) left paraproct with large, round and flat extension, latter without.

\section{Etymology}

The specific name is derived from the Latin word 'furcatus' and refers to the shape of the left paraproct plate looking like a fork.

\section{Type material}

\section{Holotype}

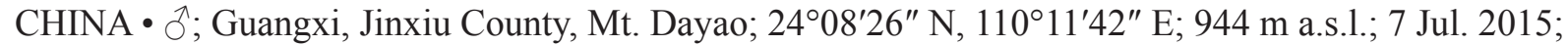
Lu Qiu and Qi-kun Bai leg.; SWU.

\section{Paratypes}

CHINA $\bullet 2 \overbrace{}^{\lambda}$; same collection data as for holotype; SWU.

\section{Description}

\section{Male}

MEASUREMENTS (mm). Male: pronotum length $\times$ width: $1.2-1.3 \times 1.3-1.4$, tegmina length: $4.5-5.2$, overall length: $5.8-6.6$. Female: pronotum length $\times$ width: $1.3 \times 1.4-1.5$, tegmina length: $4.2-4.5$, overall length: $5.6-5.9$.

Coloration. Body dark brown, eyes black, antennae dark brown (Fig. 6A-B). Head dark reddish brown (Fig. 6C). Pronotum dark brown, lateral borders of pronotum hyaline (Fig. 6D). Tegmina brown (Fig. 6E). Wings with costal field and appendicular field infuscated, other part pale brown, with veins brown (Fig. 61). Abdominal sterna, and cerci dark brown; legs dark yellowish brown (Fig. 6B).

HEAD AND THORAX. Interocular space greater than distance between antennal sockets (Fig. 6C). Fourth and fifth maxillary palpi almost equal in length, shorter than third maxillary palpus, fifth maxillary palpus strongly thicker than fourth, which is nearly triangular (Fig. 6G). Pronotum subcircular (Fig. 6D). Tegmina with veins indistinct; wings with radial veins slightly indistinct, $\mathrm{CuA}$ ending at $\mathrm{CuP}$, (Fig. 6EF, I). Front femur type B2 (Fig. 6H). Pulvilli absent, arolia present.

MaLE ABdomen AND GENITALIA. Supra-anal plate longer, left paraproct with large, round and flat extension, right one simple sheet-like (Fig. 6J-K). Subgenital plate fan-shaped, nearly symmetrical; styli with length about $1 / 3$ of interstylar space, interstylar margin arcuate (Fig. 6L). Phallomere complex, L1 triangle with 

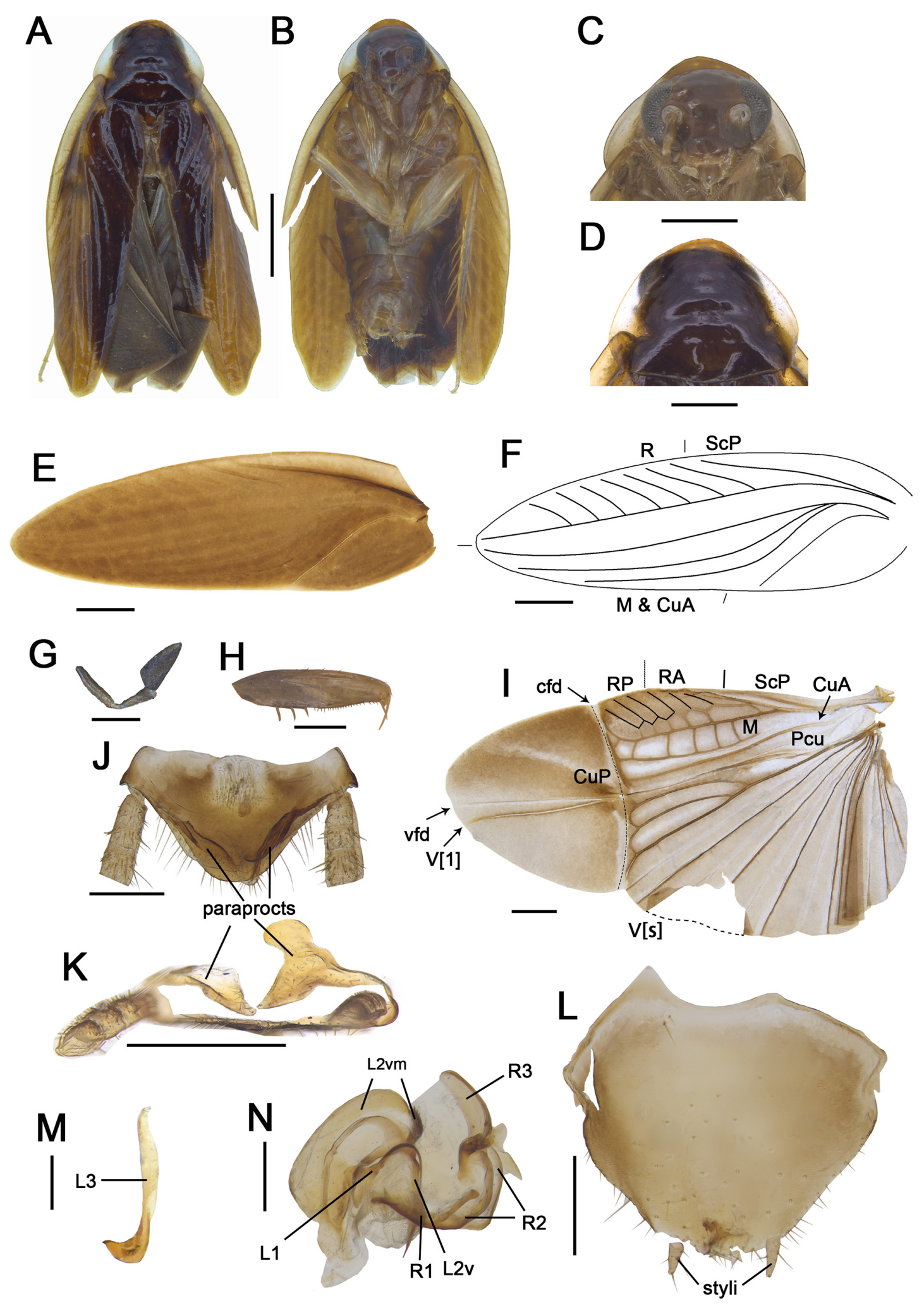

Fig. 6. Anaplecta furcata Deng \& Che sp. nov., holotype, $\widehat{\partial}$ (SWU). A. Habitus, dorsal view. B. Habitus, ventral view. C. Head, ventral view. D. Pronotum, dorsal view. E. Tegmina. F. Tegmina vein. G. Maxillary palp. H. Front femur, ventral view. I. Wings. J. Supra-anal plate, dorsal view. K. Supra-anal plate. L. Subgenital plate, ventral view. M. Hook, ventral view. N. Left and right phallomere, ventral view. Scale bars: $A-B=1 \mathrm{~mm} ; \mathrm{C}-\mathrm{F}, \mathrm{H}-\mathrm{N}=0.5 \mathrm{~mm} ; \mathrm{G}=0.25 \mathrm{~mm}$. 
DENG W. et al., Eight new species of Anaplecta (Blattodea: Blattoidea: Anaplectidae) from China

slender and curved filamentary structure, L2v long and slender, L2vm wide with brush-like structure, L3 with apex of uncinate part enlarged and blunt; R1 arc-shaped, R2 irregular bone sheet and weakly sclerotized, R3 short simple sheet-like (Fig. 6M-N).

\title{
Distribution
}

China (Guangxi).

\author{
Anaplecta cruciata Deng \& Che sp. nov. \\ urn:1sid:zoobank.org:act:A229787B-5350-4522-B068-09747DDF41EE
}

Fig. 7

\section{Diagnosis}

This species can be easily separated from other species by the left phallomere with a strongly thickened filamentary structure, which is crossed with another bone fragment.

\section{Etymology}

The specific name is derived from the Latin word 'cruciatus' and refers to the crossed bone fragments (L1 and L2v) of the left phallomere.

\section{Type material}

\section{Holotype}

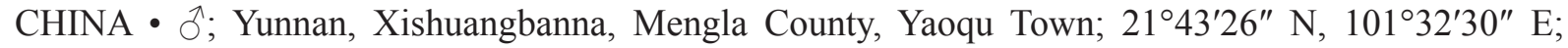
820 m a.s.1.; 10 May 2015; Jian-yue Qiu leg.; SWU.

\section{Paratypes}

CHINA - Yunnan • $1 \delta^{\lambda}$; Xishuangbanna, Mengla County, Shangyong Town; $21^{\circ} 14^{\prime} 36^{\prime \prime}$ N, $101^{\circ} 42^{\prime 2} 26^{\prime \prime}$ E; 792 m a.s.l.; Jian-yue Qiu leg.; SWU • 8 $\widehat{\jmath}, 4$ 우; same collection data as for holotype; SWU.

\section{Description}

\section{Male}

Measurements $(\mathrm{mm})$. Male: pronotum, length $\times$ width: $1.2-1.3 \times 1.3-1.4$, tegmina length: $4.5-5.2$, overall length: 5.8-6.6. Female: pronotum, length $\times$ width: $1.3 \times 1.4-1.5$, tegmina length: $4.2-4.5$, overall length: 5.6-5.9.

Coloration. Body dark brown, eyes black, antennae dark brown (Fig. 7A-B). Vertex, frons reddish brown; clypeus yellowish brown (Fig. 7C). Pronotum dark brown, lateral borders of pronotum hyaline (Fig. 7D). Tegmina pale dark brown, lateral margins of tegmina nearly hyaline (Fig. 7E). Wings with costal field and appendicular field infuscated, other part yellowish brown, with veins brown (Fig. 7I). Legs yellowish brown, cerci dark yellowish brown (Fig. 7B, J).

HEAD AND THORAX. Interocular space greater than distance between antennal sockets (Fig. 7C). Fourth and fifth maxillary palpi subequal in length, longer than third maxillary palpus, fifth maxillary palpus slightly thicker than fourth, which is nearly oval (Fig. 7G). Pronotum subparabolic (Fig. 7D). Tegmina with veins indistinct; wings with radial veins basically distinct, $\mathrm{CuP}$ and $\mathrm{CuA}$ merging into one venation (Fig. 7E-F, I). Front femur type B2 (Fig. 7H). Pulvilli absent, arolia present.

Male abdomen and Genitalia. Paraprocts different, the left paraproct with small process (Fig. 7J). Subgenital plate asymmetrical, styli with length about $1 / 2$ of interstylar space, interstylar margin arcuate 

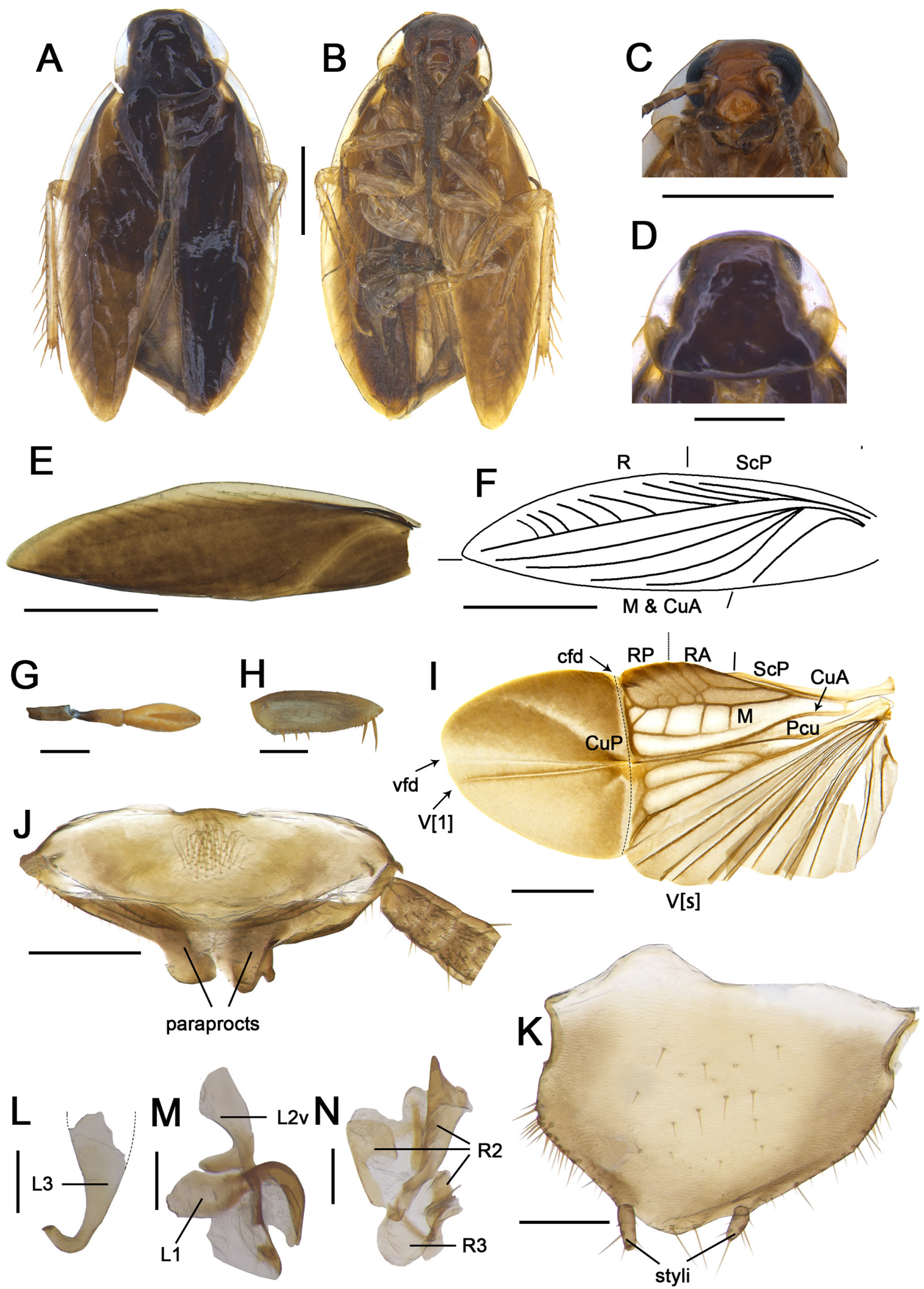

Fig. 7. Anaplecta cruciata Deng \& Che sp. nov., holotype, $\hat{\sigma}$ (SWU). A. Habitus, dorsal view. B. Habitus, ventral view. C. Head, ventral view. D. Pronotum, dorsal view. E. Tegmina. F. Tegmina vein. G. Maxillary palp. H. Front femur, ventral view. I. Wings. J. Supra-anal plate, dorsal view. K. Subgenital plate, ventral view. L. Hook, ventral view. M. Left phallomere, ventral view. N. Right phallomere, ventral view. Scale bars: A-C $=1 \mathrm{~mm}$; D-F, I-K $=0.5 \mathrm{~mm} ; \mathrm{G}-\mathrm{H}=0.2 \mathrm{~mm} ; \mathrm{L}-\mathrm{N}=0.25 \mathrm{~mm}$. 
(Fig. 7K). Phallomere simple, L1 with filamentary structure strongly thickened, which is crossed with another bone fragment (L2v), L2d and L2vm degraded, L3 robust with apex of uncinate part enlarged and blunt; R1 absent, R2 irregular bone sheet, weakly sclerotized, R3 short simple sheet-like (Fig. 7L-N).

\title{
Distribution
}

China (Yunnan).

\author{
Anaplecta nigra Deng \& Che sp. nov. \\ urn:1sid:zoobank.org:act:2111494F-7E1F-48B2-9F27-8FD748D46317
}

Fig. 8

\section{Diagnosis}

This species resembles A. basalis but can be distinguished from it by: 1) subgenital plate distinctly asymmetrical with posterior margin strongly produced at middle, while slightly asymmetrical with posterior margin more or less produced in A. basalis; 2 ) supra-anal plate with paraprocts nearly identical, distinctly different for $A$. basalis.

\section{Etymology}

The specific name is derived from the Latin word 'niger' and refers to the black markings at the base of tegmina.

\section{Type material}

\section{Holotype}

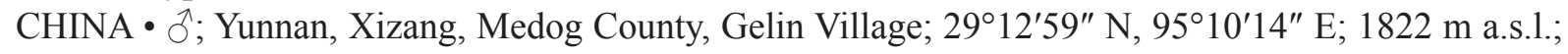
16 Jul. 2016; Jian-yue Qiu and Hao Xu leg.; SWU.

\section{Paratype}

CHINA • 1 \%; same collection data as for holotype; SWU.

\section{Description}

\section{Male}

MEASUREMENTS $(\mathrm{mm})$. Male: pronotum length $\times$ width: $1.3 \times 1.9$, tegmina length: 5.9 , overall length: 6.5 . Female: pronotum length $\times$ width: $1.4 \times 1.8$, tegmina length: 5.9, overall length: 6.5 .

Coloration. Body yellowish brown, eyes black, antennae dark brown (Fig. 8A-B). Face yellowish brown (Fig. 8C). Pronotum yellowish-brown lateral borders of pronotum hyaline (Fig. 8D). Two thirds of tegmina yellowish brown, remaining dark brown (Fig. 8G). Wings with costal field and appendicular field infuscated, other part pale brown, with veins brown (Fig. 8H). Abdominal sterna yellowish brown with black borders; legs pale yellowish brown; cerci brown (Fig. 8B).

HEAD AND THORAX. Interocular space greater than distance between antennal sockets (Fig. 8C). Fourth and fifth maxillary palpi subequal in length, shorter than third maxillary palpus, fifth maxillary palpus slightly thicker than fourth, which is nearly triangular (Fig. 8E). Pronotum nearly oval (Fig. 8D). Tegmina with veins distinct; wings with radial veins nearly distinct, $\mathrm{CuA}$ ending at $\mathrm{CuP}$, (Fig. 8G-H). Front femur type B2 (Fig. 8F). Pulvilli absent, arolia present.

Male abdomen and Genitalia. Supra-anal plate with paraprocts almost identical, simple sheet-like (Fig. 8I). Subgenital plate fan-shaped, distinctly asymmetrical with posterior margin strongly produced 

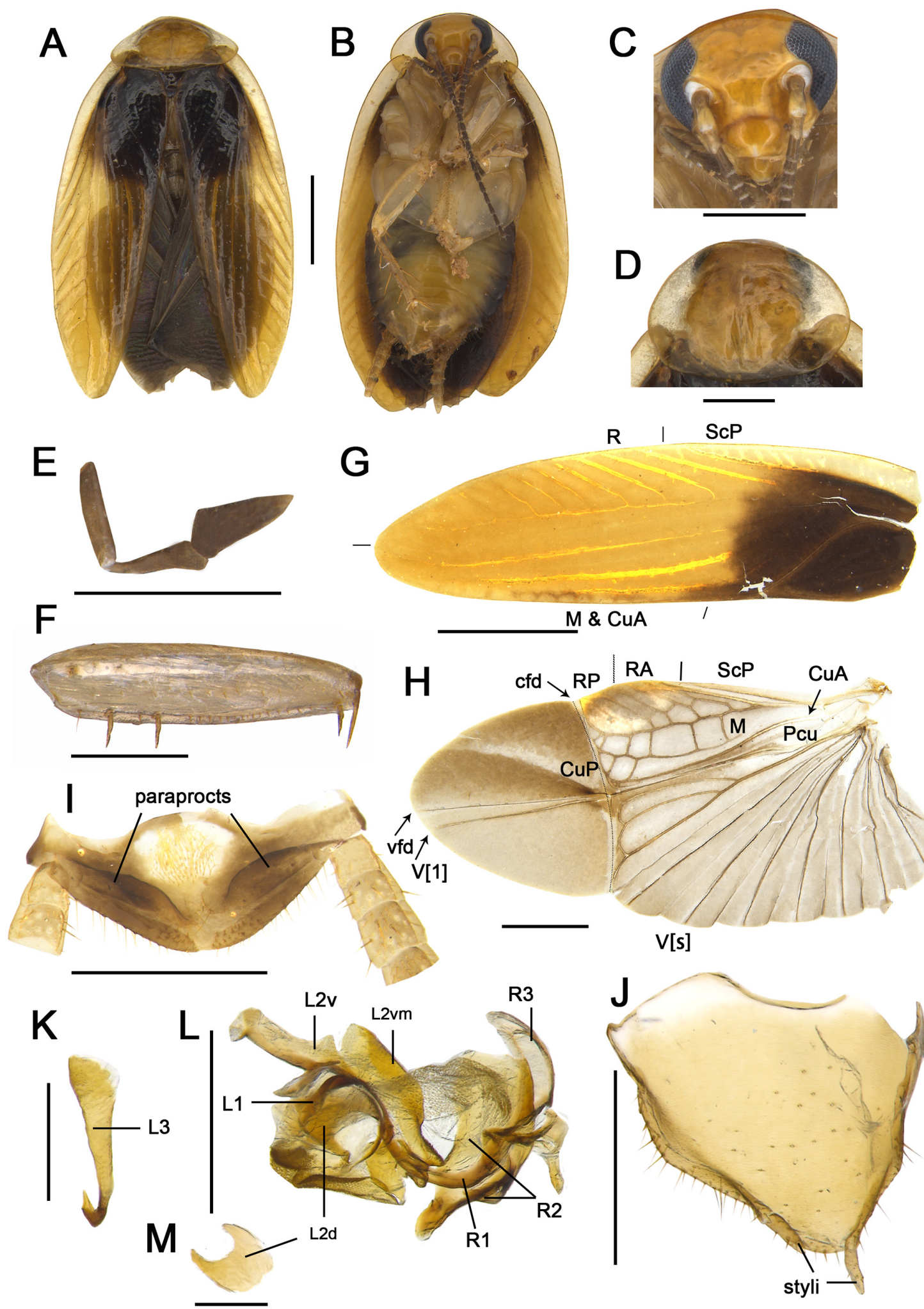

\section{CUA}


at middle; two styli long, left stylus skewed to hind margin of subgenital plate, distance between two styli very short (Fig. 8J). Phallomere complex, L1 small with slender and curved filamentary structure, L2v and L2vm broad, L2d dentate and sheet-like, L3 robust with apex of the uncinate part tapering; R1 arc-shaped, R2 irregular bone sheet and weakly sclerotized, R3 short simple sheet-like (Fig. 8K-M).

\title{
Distribution
}

China (Xizang).

\author{
Anaplecta bicolor Deng \& Che sp. nov. \\ urn:lsid:zoobank.org:act:9EAA3F86-9C7F-453E-BA98-651CAF105F17
}

Fig. 9

\section{Diagnosis}

This species resembles $A$. basalis in disk of pronotum with anterior half crimson-brown and posterior half yellowish-white, but can be distinguished by the following characters: 1) tegmina without black markings in Anaplecta bicolor Deng \& Che sp. nov., the base of tegmina with black markings in A. basalis; 2) phallomere with a cluster of setae in former, the latter without; 3) L2d and L2vm absent in former, present in latter.

\section{Etymology}

The specific name is derived from the Latin word 'bicolor' and refers to the pronotum with the anterior half crimson-brown and the posterior half yellowish white.

\section{Type material}

\section{Holotype}

CHINA • ${ }^{\top}$; Yunnan, Xishuangbanna, Mengla County; 2127'46" N, 101³3'19" E; 668 m a.s.1.; 16 Jul. 2004; Zong-qing Wang leg.; SWU.

\section{Paratypes}

CHINA - Yunnan • 1 ; ; same collection data as for holotype; SWU $11 \hat{\jmath}, 1 \uparrow$; Xishuangbanna, Mengla

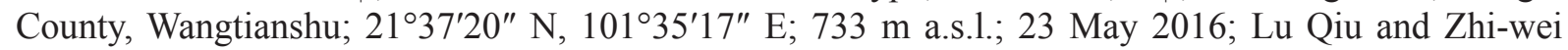
Qiu leg.; SWU.

\section{Description}

\section{Male}

MEASUREMENTS $(\mathrm{mm})$. Male: pronotum length $\times$ width: $1.3 \times 1.8$, tegmina length: 5.2, overall length: 6.2 .

Coloration. Body reddish brown, eyes black, antennae yellow (Fig. 9A-B). Vertex, frons reddish brown; clypeus yellowish brown (Fig. 9D). Disk of pronotum with anterior half reddish brown, posterior half yellowish white, lateral borders of pronotum hyaline (Fig. 9C). Tegmina pale reddish brown, lateral margins of tegmina hyaline (Fig. 9E). Wings with costal field and appendicular field infuscated, other part pale gray, with veins yellow (Fig. 9H). Legs and cerci yellowish brown (Fig. 9B).

HEAD AND THORAX. Interocular space greater than distance between antennal sockets (Fig. 9D). Pronotum subcircular (Fig. 9C). Tegmina with veins basically distinct; wings with radial veins slightly indistinct, $\mathrm{CuP}$ and $\mathrm{CuA}$ merging into one venation (Fig. 9E-F, H). Front femur type B2 (Fig. 9G). Pulvilli absent, arolia present.

Male abdomen AND Genitalia. Supra-anal plate with paraprocts almost identical, slender piece of bone sheet connected with each paraproct (Fig. 9I). Subgenital plate fan-shaped, asymmetrical, hind margin 

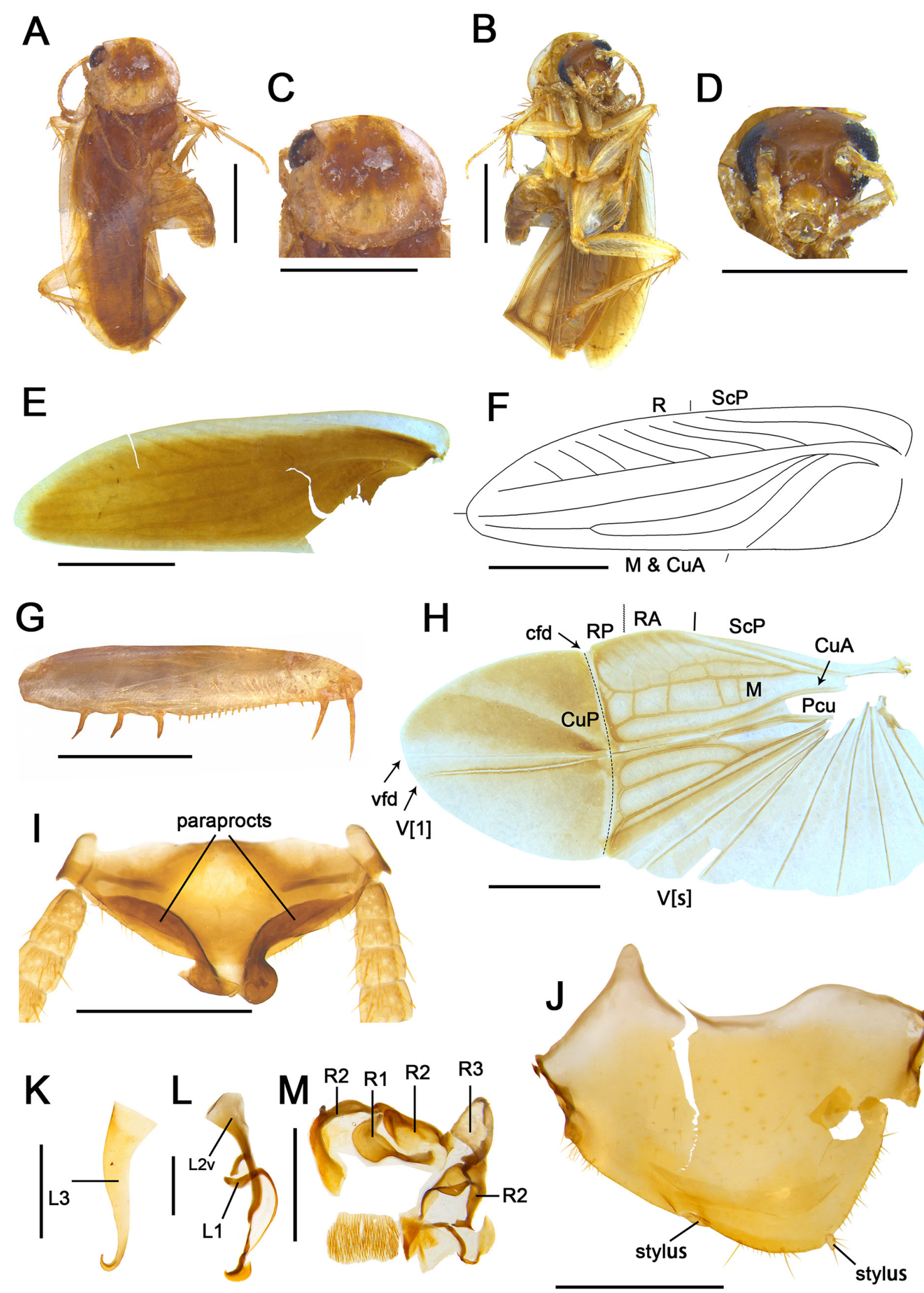

$\mathrm{H}$ 
extending beyond end of left stylus, but almost equal to right; two styli very small, distance between them long (Fig. 9J). Phallomere complex, L1 small with slender and curved filamentary structure, L2v clubbed, L2d and L2vm absent, L3 robust, uncinate part with apex enlarged and sharp; R1 irregular and middle wide, R2 irregular bone sheet, weakly sclerotized, R3 short simple sheet-like. Moreover, cluster of setae in right phallomere (Fig. 9K-M).

\section{Distribution}

China (Yunnan).

Anaplecta omei Bey-Bienko, 1958

Fig. 10A-B, E

Anaplecta omei Bey-Bienko, 1958: 591 (type locality: Sichuan, China).

\section{Diagnosis}

This species is widely distributed in southern China and has a yellowish-brown body (Fig. 10A-B). This species can be distinguished from other species by the right paraproct with many short, stout spines on curly posterior margin and left paraproct sheet-like (Fig. 10E).

\section{Material examined}

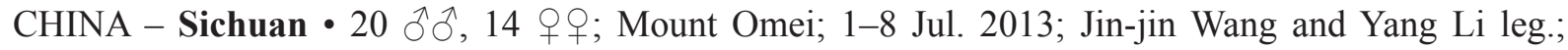
SWU. - Fujian • 30 ô $\widehat{0}, 10$ 우; Mount Wuyi; 5-11 Jul. 2013; Shun-hua Gui and Yan Shi leg.; SWU. - Guangxi - 8 $\lesssim, 10$ 우; Jinxiu County; 1-5 May 2014; Shun-hua Gui, Xin-ran Li and Jian-yue Qiu leg.; SWU. - Jiangsu • 47 $\widehat{\partial}, 31$ q 9 ; Nanjing; 7-14 Jul. 2014; Yan Shi, Xin-ran Li and Jian-yue

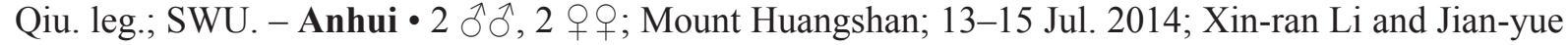

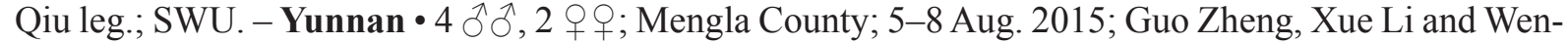
yue Zhu leg.; SWU. - Chongqing • 98 ồ, 30 q o+; Beibei; 2012-2019; laboratory staff leg.; SWU.

\section{Distribution}

China (Anhui, Chongqing, Fujian, Jiangsu, Sichuan, Yunnan).

Anaplecta basalis Bey-Bienko, 1969

Fig. 10C-D

Anaplecta basalis Bey-Bienko, 1969: 839

(type locality: Yunnan, China).

\section{Diagnosis}

This species is easily separated from other species by its pale-yellow body. It can be distinguished by two other characters: 1) disk of pronotum with anterior half crimson-brown, posterior half yellowishwhite; 2) base of tegmina with black markings (Fig. 10C-D).

\section{Material examined}

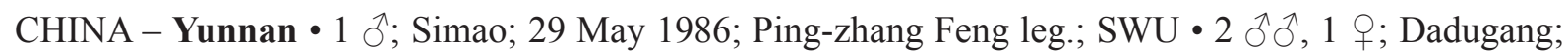

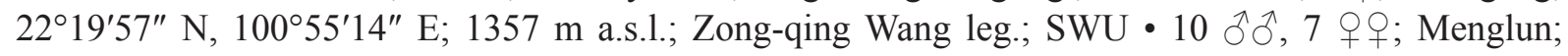
2154'58" N, 101'14'32" E; 624 m a.s.1.; 27 Apr. 2019; Zi-long Bai, Zhi-gang Chen, Cheng Wang, Yanfeng Tong and Hao Yu leg.; SWU. 


\section{Distribution}

China (Yunnan).

\section{Discussion}

DNA-based analyses resolved the vast majority of samples of Anaplecta to a putative species, but there is a difference in species delimitation between the two molecular methods used. Four samples of A. corneola Deng \& Che sp. nov. (ZQ, JFL1, WY, MS) were recovered as two MOTUs in GMYC, but only one in ABGD. In spite of the high morphological similarity of the four samples, the differences exhibited in the four samples of $A$. corneola Deng \& Che sp. nov. were determined to be intraspecific variation after a critical examination on the $\mathrm{R} 1$. The genetic distances among three samples of $A$. corneola Deng \& Che sp. nov. (ZQ, WY, MS) are 0.3\%-2\% (Supplementary File 1) which was distinctly lower than the interspecific distance (16.8\% to $31.8 \%$ ); only the genetic distances between sample JFL1 and the other three samples (ZQ, WY, MS) are larger (Supplementary File 1: 6.3\%-6.6\%), but still distinctly lower than the interspecific distance. And there is the fact that the R1 of the samples from ZQ and JFL1 does not exhibit any difference (Fig. 10F, I), although a larger genetic divergence exists between them (Supplementary File 1: 6.5\%). Also, there is a conflict between the morphological identification and the molecular species delimitation in our study, mainly in specimens of A. staminiformis Deng \& Che sp. nov. These were treated as two morphospecies, firstly on the basis of a difference of L2d (Fig. 3L, O).

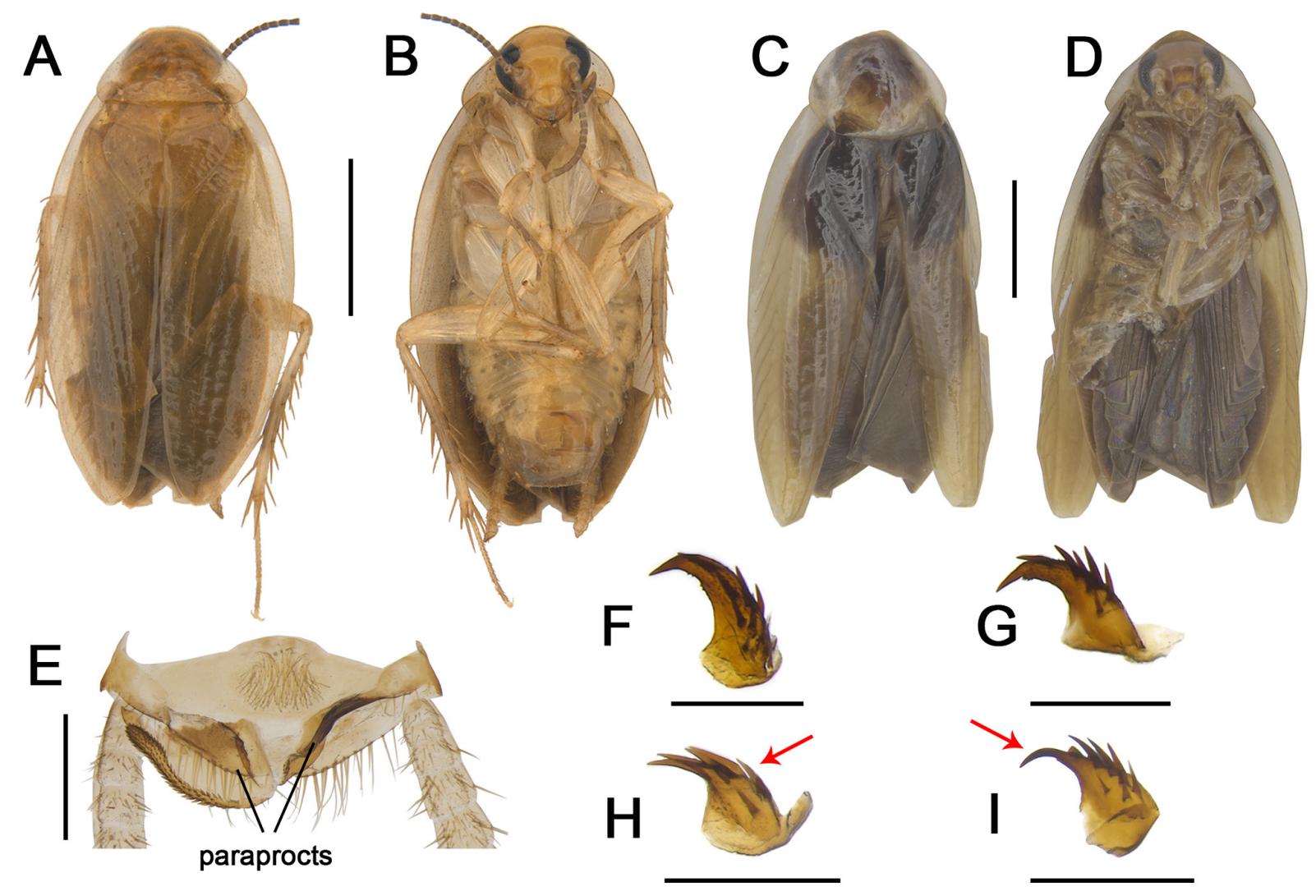

Fig. 10. A-B, E. Anaplecta omei Bey-Bienko, 1958. A. Habitus, dorsal view. B. Habitus, ventral view. E. Supra-anal plate, dorsal view. - C-D. Anaplecta basalis Bey-Bienko, 1969. C. Habitus, dorsal view. D. Habitus, ventral view. $-\mathbf{F}-\mathbf{I}$. Comparison of $\mathrm{R} 1$ of $A$. corneola Deng \& Che sp. nov. from different localities. F. Guangdong Prov., Zhaoqing City (ZQ). G. Hainan Prov., Ledong County, Mt. Jianfengling (JFL1). H. Hunan Prov., Chenzhou City, Yizhang County, Mangshan National Forest Park (MS). I. Fujian Prov., Wuyishan City, (WY). Scale bars: A-B $=2 \mathrm{~mm} ; \mathrm{C}-\mathrm{D}=1 \mathrm{~mm} ; \mathrm{E}=0.5 \mathrm{~mm} ; \mathrm{F}-\mathrm{I}=0.25 \mathrm{~mm}$. 
DENG W. et al., Eight new species of Anaplecta (Blattodea: Blattoidea: Anaplectidae) from China

However, we suggest they should be considered as one species via DNA-based analyses because of minor genetic distances (Supplementary File 1: 1.9\%). Accordingly, a comprehensive analysis, including morphological or molecular methods, may help to delimit the species of Anaplecta successfully.

Members of the genus Anaplecta are widely distributed all over the world. Our collecting data reveal that species of Anaplecta have a strong migration ability and adaptability. For example, A. omei shows a wide distribution in southern China (Chongqing City, Jiangsu Prov., Fujian Prov., Sichuan Prov., Guangxi Prov., Anhui Prov.). Similarly, samples of A. corneola Deng \& Che sp. nov. were collected across four provinces of China which are geographically distant from each other, especially the sample JFL from Hainan Province (an isolated island in the South China Sea). Therefore, the gene flow might be hindered by natural barriers among geographically distant populations, which may account for the larger intraspecific genetic distance among these four samples.

\section{Acknowledgements}

The many collectors mentioned in the text are thanked for their efforts in the field and their generous offers of specimens. We also thank Dr John Richard Schrock (Department of Biological Sciences, Emporia State University, Kansas) for revising the English. This study is supported by the National Natural Science Foundation of China (No. 31772506) and a Program of the Ministry of Science and Technology of the People's Republic of China (2015FY210300).

\section{References}

Beccaloni G.W. 2014. Cockroach species file online. Ver. 5.0/5.0.

Available from http://Cockroach.SpeciesFile.org [accessed 29 Jan. 2019].

Bey-Bienko G.Y. 1958. Results of the Chinese-Soviet Zoological-Botanical Expeditions of 1955-56 to southwestern China. Blattoidea of Szechuan and Yunnan II: 582-597.

Bey-Bienko G.Y. 1969. New genera and species of cockroaches (Blattoptera) from tropical and subtropical Asia. Entomologica Obozrenie 48: 831-862.

Bourguignon T., Tang Q., Ho S.Y.W., Juna F., Wang Z.Q., Arab D.A., Cameron S.L., Walker J., Rentz D., Evans T.A. \& Lo N. 2018. Transoceanic dispersal and plate tectonics shaped global cockroach distributions: evidence from mitochondrial phylogenomics. Molecular Biology and Evolution 35: 1-14. https://doi.org/10.1093/molbev/msy013

Bruijning C.F.A. 1948. Studies on Malayan Blattidae. Zoologische Mededelingen 29: 1-174.

Brunner von Wattenwyl C. 1865. Nouveau système des Blattaires. G. Braunmüller Vienna.

Burmeister H. 1838. Handbuch der Entomologie II (2): 397-756. Reimer, Berlin.

Djernæs M. 2018. Biodiversity of Blattodea - the Cockroaches and Termites. In: Foottit R.G. \& Adler P.H. (eds) Insect Biodiversity: Science and Society: 359-387. Wiley and Sons Ltd, New Jersey. https://doi.org/10.1002/9781118945582.ch14

Djernæs M., Klass K.-D. \& Eggleton P. 2015. Identifying possible sister groups of Cryptocercidae+ Isoptera: A combined molecular and morphological phylogeny of Dictyoptera. Molecular Phylogenetics and Evolution 84: 284-303. https://doi.org/10.1016/j.ympev.2014.08.019

Drummond A.J. \& Rambaut A. 2007. BEAST: Bayesian evolutionary analysis by sampling trees. $B M C$ Evolutionary Biology 7: 214. https://doi.org/10.1186/1471-2148-7-214

Ezard T.H.G., Fujisawa T. \& Barraclough T.G. 2009. Splits: Species Limits by Treshold Statistics. Available from http://R-Forge.R-project.org/projects/splits/ [accessed 5 Jul. 2017]. 
Grandcolas P. 1993. Monophylie et structure phylogenetique des [Blaberinae + Zetoborinae + Gyninae + Diplopterinae] (Dictyoptera: Blaberidae). Annales de la Société entomologique de France (NS) 29 (2): 195-222.

Grandcolas P. 1996. The phylogeny of cockroach families: a cladistic appraisal of morpho-anatomical data. Canadian Journal of Zoology 74: 508-527. https://doi.org/10.1139/z96-059

Grandcolas P. 1997. The monophyly of the subfamily Perisphaeriinae (Dictyoptera: Blattaria: Blaberidae). Systematic Entomology 22: 123-130. https://doi.org/10.1046/j.1365-3113.1997.d01-28.x

Grandcolas P. 1999. Reconstructing the past of Cryptocercus (Blattaria: Polyphagidae): phylogenetic histories and stories. Annals of the Entomological Society of America 92: 303-307.

https://doi.org/10.1093/aesa/92.3.303

Hanitsch R. 1915. Malayan Blattidae. Part I. Journal Straits Branch Royal Asiatic Society 69: 17-178.

Hanitsch R. 1929. Fauma Sumatrensis. (Beitrag No. 63). Blattidae. Tijdschrift voor Entomologie 72: 263-303.

Hanitsch R. 1930. Über eine Sammlung malayischer Blattiden des Dresdner Museums. (Orth.). Stettiner Entomologische Zeitung 91: 177-195.

Hanitsch R. 1931. On a Collection of Malayan Blattidae from the British Museum (Natural History). The Annals and Magazine of Natural History 7: 385-408.

Hanitsch R. 1932. Beccari and Modigliani's collection of Sumatran Blattidae in the museo civico, Genoa. Annali del Museo Civico di Storia Naturale di Genova 36: 48-92.

Hebard M. 1929. Studies in Malayan Blattidae (Orthoptera). Proceedings of the Academy of Natural Sciences of Philadelphia 81: 1-109.

Kimura M. 1980. A simple method for estimating evolutionary rates of base substitutions through comparative studies of nucleotide sequences. Journal of Molecular Evolution 16: 111-120.

https://doi.org/10.1007/BF01731581

Kirby W.F. 1904. A synonymic catalogue of Orthoptera Vol. 1. Orthoptera Euplexoptera Cursori, et Gressoria 18: 61-209.

Lanfear R., Calcott B., Ho S.Y. \& Guindon S. 2012. PartitionFinder: combined selection of partitioning schemes and substitution models for phylogenetic analyses. Molecular Biology and Evolution 29: 16951701. https://doi.org/10.1093/molbev/mss020

Li X.R., Zheng Y.H., Wang C.C. \& Wang Z.Z. 2018. Old method not old-fashioned: parallelism between wing venation and wing-pad tracheation of cockroaches and a revision of terminology. Zoomorphology 137 (4): 1-15. https://doi.org/10.1007/s00435-018-0419-6

McKittrick F.A. 1964. Evolutionary studies of cockroaches. Cornell University Agricultural Experiment Station Memoir 389: 1-197.

Princis K. 1960. Zur systematik der blattarien. Eos Transactions American Geophysical Union 36 (4): 427-449.

Princis K. 1965. Blattariae: Subordo Blaberoidea: Fam.: Oxyhaloidae, Panesthiidae, Cryptocercidae, Chorisoneuridae, Oulopterygidae, Diplopteridae, Anaplectidae, Archiblattidae, Nothoblattidae. In: Beier M. (ed.) Orthopterorum Catalogus. Pars 7: 284-400. W. Junk, The Hague.

Pons J., Barraclough T.G., Gomezzurita J., Cardoso A., Duran D.P., Hazell S., Kamoun S., Sumlin W.D. \& Vogler A.P. 2006. Sequence-based species delimitation for the DNA taxonomy of undescribed insects. Systematic Biology 55: 595-609. https://doi.org/10.1080/10635150600852011 
DENG W. et al., Eight new species of Anaplecta (Blattodea: Blattoidea: Anaplectidae) from China

Puillandre N., Lambert A., Brouillet S. \& Achaz G. 2012. ABGD, Automatic Barcode Gap Discovery for primary species delimitation. Molecular Ecology 21: 1864-1877.

https://doi.org/10.1111/j.1365-294X.2011.05239.x

R Code Team C. 2013. R: A Language and Environment for Statistical Computing. R Foundation for Statistical Computing, Vienna.

Roth L.M. 1990. Revisionary studies on Blattellidae (Blattaria) from the Indo-Australian region. Memoirs of the Queensland Museum 28: 597-663.

Roth L.M. 1996. The cockroach genera Anaplecta, Anaplectella, Anaplectoidea, and Malaccina (Blattaria, Blattellidae: Anaplectinae and Blattellinae). Oriental Insects 30: 301-372.

Roth L.M. 2003. Systematics and phylogeny of cockroaches (Dictyoptera: Blattaria). Oriental Insects 37: 1-186. https://doi.org/10.1080/00305316.2003.10417344

Saussure H.D. \& Zehntner L. 1895. Revision de la tribu des Perisphaeriens (Insectes Orthoptéres de la famille des Blattides). Revue suisse de Zoologie 3: 1-59.

Shelford R. 1906. Studies of the Blattidae. Remarks on the sub-families Ectobiinae and Phyllodromiinae. Transactions of the Entomological Society of London 54 (2): 231-278.

https://doi.org/10.1111/j.1365-2311.1906.tb02474.x

Shelford R. 1908. New species of Blattidae in the collection of the Deutsche Entomologische NationalMuseum. (Orthoptera). Deutsche Entomologische Zeitschrift 1908 (1): 115-131.

Available from https://www.biodiversitylibrary.org/page/33769554 [accesed 21 Sep. 2020].

Shelford R. 1909. Descriptions of some new genera and species of Blattidae. (Orth). Deutsche Entomologische Zeitschrift 1909 (5): 611-624.

Available from https://www.biodiversitylibrary.org/page/33103293 [accessed 21 Sep. 2020].

Shiraki T. 1931. Orthoptera of the Japanese Empire. II. Blattidae. Insecta Matsumurana 4 (4): 171-209.

Stamatakis A., Hoover P. \& Rougemont J. 2008. A rapid bootstrap algorithm for the RAxML web servers. Systematic Biology 57: 758-771. https://doi.org/10.1080/10635150802429642

Walker F. 1868. Catalogue of the Specimens of Blattariae in the Collection of the British Museum. The Trustees of the British Museum, London. https://doi.org/10.5962/bhl.title.8495

Wang Z.Q., Shi Y., Qiu Z.W., Che Y.L. \& Lo N. 2017. Reconstructing the phylogeny of Blattodea: robust support for interfamilial relationships and major clades. Scientific Reports 7 (1): 3903.

https://doi.org/10.1038/s41598-017-04243-1

Manuscript received: 8 October 2019

Manuscript accepted: 18 August 2020

Published on: 9 October 2020

Topic editor: Nesrine Akkari

Desk editor: Kristiaan Hoedemakers

Printed versions of all papers are also deposited in the libraries of the institutes that are members of the EJT consortium: Muséum national d'histoire naturelle, Paris, France; Meise Botanic Garden, Belgium; Royal Museum for Central Africa, Tervuren, Belgium; Royal Belgian Institute of Natural Sciences, Brussels, Belgium; Natural History Museum of Denmark, Copenhagen, Denmark; Naturalis Biodiversity Center, Leiden, the Netherlands; Museo Nacional de Ciencias Naturales-CSIC, Madrid, 
Spain; Real Jardín Botánico de Madrid CSIC, Spain; Zoological Research Museum Alexander Koenig, Bonn, Germany; National Museum, Prague, Czech Republic.

\section{Supplementary File}

Supplementary File 1: Table showing the genetic divergence (K2P) and bootstrap method of species of Anaplecta Burmeister, 1838 using cytochromecoxidase subunit I (COI) gene sequences in MEGA. https://doi.org/10.5852/ejt.2020.720.1117.2911 